\title{
CINCO SIGLOS EN LA HISTORIA DE LOS DICCIONARIOS BILINGÜES LATÍN-ESPAÑOL Y ESPAÑOL-LATÍN (XV-XIX)
}

\author{
Antonia $M^{a}$ Medina Guerra \\ Universidad de Málaga
}

\begin{abstract}
RESUMEN
En este recorrido por la lexicografia bilingüe con el latín y el español, se describen los repertorios lexicográficos más relevantes desde siglo XV al XIX y se intentan establecer sus fuentes y epigonos. Se pone asi de manifiesto, no solo hasta qué punto la labor de Nebrija no fue comprendida del todo -por más que sus diccionarios siguieran publicándose en el siglo XIX-, sino también cómo en esta parcela nuestra lexicografia se muestra, en gran parte, deudora de la italiana, inspirándose primero en los grandes diccionarios monolingües latinos y después en los bilingües y plurilingües publicados en Italia.
\end{abstract}

Palabras clave: lexicografia bilingüe; diccionarios bilingües; lexicografia españollatin; diccionarios latín-español; diccionarios español-latín.

ABSTRACT

This article studies Latin and Spanish bilingual lexicography. It describes the most important lexicographic repertories from the $15^{\text {th }}$ century up to the $19^{\text {th }}$ century, confirming their sources and epigones. It proves how Nebrija's work was not totally understood, although his dictionaries were published until the $19^{\text {th }}$ century, and how the lexicography of these centuries owed a lot to the Italian one, as it followed both the great Latin monolingual dictionaries and the bilingual or multilingual ones published in Italy.

Keywords: bilingual lexicography; bilingual dictionaries; Spanish-Latin lexicography; Latin-Spanish dictionaries; Spanish-Latin dictionaries.

No podemos iniciar este recorrido por la lexicografía bilingüe latino-española, sin reconocer la importancia en el estudio y la enseñanza del latín de los glosarios medievales, como el Glosario de Toledo, el Glosario de Palacio y el Glosario de El Escorial ${ }^{1}$, por más

\footnotetext{
${ }^{1}$ Estos tres glosarios fueron publicados con un interesante estudio preliminar de Américo Castro en 1936 (cito por la edición facsimilar de 1991). El Glosario de Toledo y el Glosario de Palacio se fechan en torno al último tercio del siglo XIV; el Glosario de El Escorial, con letra del siglo XV, es "[...] el más extenso e importante [...] y el más pulcramente escrito de los tres glosarios" (Castro 1991: XX-XXII).
} 
que, como veremos, los primeros diccionarios con el latín y el español entronquen con la lexicografía europea monolingüe y no con los glosarios bilingües (Alvar Ezquerra 2002a: 90). En efecto, la historia de nuestros diccionarios se inicia al amparo de los grandes repertorios latinos de la Edad $\mathrm{Media}^{2}$, que ven la luz en Italia y que se extienden por toda Europa, especialmente a partir de la invención de la imprenta, como el Elementarium doctrinae (e)rudimentum ${ }^{3}$ de Papias, el Liber derivationum ${ }^{4}$ de Hugución de Pisa o el Catholicon $^{5}$ de Juan Balbi, deudores a su vez de la labor emprendida en siglo VI por San Isidoro de Sevilla (Gemmingen 2003: 159-161). En España, por tanto, se utilizan y se conocen las mismas grandes obras lexicográficas medievales que en el resto de Europa, y hasta finales del siglo XV no se siente la necesidad de redactar diccionarios destinados de manera específica a paliar el escaso dominio que del latín tienen los españoles.

\section{SIGLO XV}

La última década del siglo XV se inicia con la publicación del primer gran diccionario con el español, el Universal vocabulario en latín y en romance del cronista real Alfonso Fernández de Palencia, que se imprime en Sevilla en $1490^{6}$. Eclipsado pronto por la enorme fama de los diccionarios de Nebrija, a esta primera edición no le siguieron otras hasta su reproducción facsimilar en 1967 (Madrid, Comisión Permanente de la Asociación de Academias de la Lengua Española, 2 v. $)^{7}$, por lo que su influencia en los repertorios posteriores es apenas perceptible.

Esta obra, escrita a instancia de la reina Isabel $^{8}$, se presenta a dos columnas; la de la izquierda encierra un diccionario monolingüe latino de unas 14000 entradas, inspirado en

\footnotetext{
${ }^{2}$ Como ha indicado Manuel Alvar Ezquerra, "La diferencia esencial entre los glosarios manuscritos y los grandes diccionarios medievales [...] es la cantidad de informaciones atesoradas. Mientras que los glosarios no eran exhaustivos, pues no tenían que serlo ya que eran unos instrumentos escolares con una finalidad concreta, los diccionarios pretendían abarcar la totalidad de la lengua" (2002b: 53). Esta concepción menos restrictiva del léxico explica también que se vayan imponiendo las denominaciones de vocabularium y dictionarium como "colección de palabras' (véanse, por ejemplo, Alvar López 1982 o Buridant 1986). En este sentido, no podemos dejar de destacar el hecho de que, ya en el siglo XI, Papias eluda intencionadamente emplear la palabra glossarium (Gemmingen 2003: 162).

${ }^{3}$ Se redactó en torno al año 1050 y de él se hicieron muchas copias manuscritas y ediciones; de estas últimas, se han indicado como las mejores una de Venecia de 1474 y una de Milán de 1476 (Olivieri 1942: 69-70, Rossebastiano Bart 1986: 113).

${ }^{4}$ Se fecha su redacción a finales del siglo XII o principios del siglo XIII.

${ }^{5}$ Según su autor, la obra se concluyó el 7 de marzo de 1286.

${ }^{6}$ Dos años antes de la muerte de su autor, cuando Palencia tenía sesenta y siete años, pues sabemos que nació en Osma el 21 de julio de 1423 (Paz y Meliá 1914: XXV).

${ }^{7}$ Cito por esta edición facsimilar.

${ }^{8}$ Y así nos lo dice en el prólogo ("Argumento de la obra emprendida"): "La muy excelente feñora doña yfabel Reyna de caftilla: y de leon: de aragon: y de fiçilia: entre las innumerables demonftraciones que ha fecho alos mortales de fus inmortales virtudes: quifo tambien añadir aquefto: que por mandado de fu tan notable alteça Alfonfo de palencia cronifta delos fechos de efpaña tomaffe cargo de interpretar los vocablos dela lengua latina
} 
una de las muchas ediciones que conoció el Elementarium doctrince (e)rudimentum de Papias (Niederehe 1986); la de la derecha, un diccionario latino-español, traducción del monolingüe y "[...] concebido solo como una ayuda para que la gente con escasos conocimientos del latín pueda entender la microestructura latina" (Gemmingen 2003: 166). No obstante, esto supone una importante novedad, porque "[...] por primera vez en toda la Romania, una lengua vulgar -el castellano, en este caso- se utiliza de manera sistemática para traducir el contenido latino [atesorado en un diccionario]" (Azorín Fernández 2000: 28).

A las entradas les sigue todo tipo de informaciones; a veces, se tratan de "[...] explicaciones literarias, gramaticales, mitológicas e históricas [...] que le dan cierto carácter incipiente de diccionario enciclopédico de humanidades grecolatinas" (Gili Gaya 1967: 6), por ejemplo, en los artículos de nombres propios de personajes históricos (Capis, Cleopatra, Gias, Sabacus), bíblicos (Dalila, Iacob, Iacobus, Nachor), mitológicos (Apollo, Jacintos, Maia, Pallas, Venus) o de lugares (Galahat, Gear, Geffen, Italia); pero en la mayoría de los casos el artículo se limita a registrar asistemáticamente la categoría gramatical, la cantidad vocálica, la etimología, la definición o descripción enciclopédica, citas o ejemplos, y en último lugar, en ocasiones, un dibujo explicativo9:

Iubare. con. b. por deleytarfe. iubare. con. u. que viene de iuuo. uas. por ayudar. pro efta en vfo de decir iuuat me. por me deleyta.

Hebenus. vna fpeçie de arbol o de madero negro enla india: y efte arbol cortado fe torna tan duro como piedra dura: es del genero femenino dela. fegunda declinacion.

Nex necis. por muerte: o pro tormento. viene de neco. Nex femenino de la tercera declinacion. Ciceron enel. 4. de los retoricos. Tiberium gracchum rempublicam adminiftratem prohibuit indigna nex diutius in ea commorari.

Sane. aduerbio por ciertamente: \& bien: \& derechuramente. Sane. por mucho valiente: porque el fano efta rezio. Terentius. en andria. Sane quidem \& fane multum.

De este modo, y como ya he dicho en otra ocasión, "[...] el Universal vocabulario surge en la historia de la lexicografía española no solo como una perfecta bisagra entre la Edad Media y el Renacimiento, sino también como el primer eslabón de una cadena ininterrumpida durante siglos, detenida solo en parte por el diccionario de Nebrija" (Medina Guerra 1991: 60) y en la que se irán engarzando, entre otras, las obras de Fernández de Santaella, Jiménez Arias o Sánchez de la Ballesta.

Con todo, y sin que ello suponga menoscabar el interés del repertorio de Palencia, hay que reconocer que es dos años más tarde, en 1492 (Salamanca), cuando se publica el que podemos considerar el primer diccionario bilingüe latín-español, el Lexicon hoc est

fegund la declaración del vulgar caftellano (que fe dize Romançe) [...]. Afli que recrecen fuerças al auctor defta obra ya venido a veiez. Cuyo fentido no ceffa de fe maravillar de las muchas operaciones tan crefcida mente prouechofas al nombre de efpaña".

9 Estos dibujos se encuentran, por ejemplo, bajo la entrada de términos procedentes de la Geometría (Ambligonius, Bafis, Cathetus, Diagonum, Diámetros, Mutilare, Pirámides, Prifma, Quadrangulus, Rumbus, Semiciclus) o de la Tipografía (Antigraphus, Afterifcus, Pereos). 
dictionarium ex sermone latino in hispaniensem o Diccionario latino-español ${ }^{10}$ de Elio Antonio de Nebrija. Para la redacción de esta obra, Nebrija no parte, que sepamos, de ninguna fuente conocida, sino de su propia competencia lingüística, fruto de sus vastas lecturas (Guerrero Ramos 1995: 50-51) y es precisamente el hecho de no tomar como referencia un repertorio monolingüe latino lo que le confiere modernidad y lo convierte en el modelo de la lexicografía bilingüe posterior (Alvar Ezquerra 2002c: 128).

Este diccionario dobla en número las entradas del Universal vocabulario, catalogando unas 28000 unidades; pero, sobre todo, el primer rasgo que salta a la vista al comparar el texto de Alfonso Fernández de Palencia con el de Nebrija es que este último prescinde de todo contenido no sustancial a lo que debe ser un artículo lexicográfico, buscando en la medida de lo posible la equivalencia entre el término latino y el español ${ }^{11}$, aunque siga conservando enlaces como interpretatur o por:

Archetypon. interpretatur ejemplar.

Emptor. oris. por el comprador.

Ludius. ij. por el efgremidor.

Mortarium. ij. por el mortero.

Ronchus. i. por el mofador.

De todas las informaciones recogidas por Palencia, en el diccionario nebrisense solo se indican, de modo sucinto a través de abreviaturas, la categoría gramatical, prestando especial atención al verbo (Irafcor. eris. por enfañarfe. d. ij.; Munio. is. muniui. por fortalecer. a. i.; Radico. as. aui. por raigar. n. v.; Uoro. as. aui. por tragar. a. i.) y también, aunque excepcionalmente, algunas referencias, por ejemplo, a Virgilio, Ovidio o Terencio, pero del todo imprecisas, ya que "Nebrija no se sentía en la obligación de poner más de lo que decía, pues lo consideraba suficiente y fuera de toda duda. Él era la autoridad en la materia, y sus palabras sentaban cátedra sin necesidad de ligarse a un texto o de acudir a otras fuentes" (Alvar Ezquerra 2002b: 61). Valgan los artículos que siguen:

Alcippe. es nombre de una muger en virgilio.

Alemon. onis. nombre de un varon en ouidio.

Alethes. e. por nombre de un varon en virgilio.

Beroe. es. es muger de doriclio en el virgilio.

Ecyra. e. por una comedia de terencio.

Mophus. por pastor en el virgilio.

\footnotetext{
${ }^{10}$ Utilizo la edición facsimilar de la de 1492 impresa en Barcelona (Puvill-Editor), en 1979.

${ }^{11} \mathrm{Si}$ bien, en ocasiones, Nebrija pone definiciones junto a las equivalencias, por ejemplo, en aquellos casos en los que no encuentra un término que tenga el mismo significado en nuestra lengua (Alvar Ezquerra 2002c: 127-128).
} 
Así, la falta de citas y ejemplos será una de las críticas más frecuentes que se hace a la labor de Nebrija en los repertorios posteriores, por ejemplo, en el prefacio del Lexicon ecclesiasticum (Salamanca, 1566), Diego Jiménez afirma:

Aunque no me detuue en citar y nombrar muchos autores, como fuelen citarfe: por feguir la brevedad con que huelgan los de efte tiempo. No que aya fido tan breue con que (conforme al Poeta) fea efcuro: como lo fue el Vocabulario del doctifsimo Antonio de Nebrija: pues que aun pongo ejemplos, con que doy a entender muy claramente todas las cofas. $^{12}$

A Elio Antonio de Nebrija le debemos también el primer diccionario en el que se toma como lengua de partida el español, el Dictionarium ex hispaniensi in latinum sermonem o Vocabulario español-latín ${ }^{13}$, aparecido en Salamanca, probablemente en torno a 1495 . Se trata de un repertorio de unas 22500 entradas, construido desde el castellano por lo que no se recogen, por ejemplo, ni muchos de los adverbios latinos en -ter ni la mayoría de los nombres propios ni las entradas latinas o griegas (a las que seguían una traducción poco precisa) del Diccionario; sin embargo, ofrece un mayor número de arabismos o de nombres religiosos de la cristiandad (García Macho 1987: 92-94). La diferente perspectiva desde la que se realiza el Diccionario y el Vocabulario se aprecia también en el hecho de que Nebrija intente en el primero adecuarse al orden alfabético del latín, mientras que la ordenación del segundo está pensada a partir del español. No hay, pues, "[...] ni siquiera sombra de que Nebrija se haya entregado a una tarea meramente automática" (Colón y Soberanas 1979: 10 ${ }^{14}$. De ahí que haya que subrayar el enorme esfuerzo que realizó para establecer por primera vez las equivalencias de las voces españolas que, por referirse a conceptos nuevos, no tenían correlatos en latín. Asimismo, el dominio de la equivalencia mejora al no figurar en el Vocabulario ni cópula ni nexo de unión entre las entradas españolas y las voces latinas (Alvar Ezquerra 2002a: 97) ${ }^{15}$ :

Aguinaldo. ftręne. arum.

Bruxa. Itrix ftrigis. lamia. ę.

Comprar. emo. is. comparo. as.

Nublado. nubilum nubili.

Ociofamente. ociofe.

Terrible. terribilis. e. horribilis. e.

\footnotetext{
${ }^{12}$ Véanse también las palabras que Manuel de Valbuena dedica al padre Rubiños, adicionador de Nebrija, en el prólogo del Diccionario universal latino-español (Madrid, 1793) y que reproduzco en este trabajo en el epígrafe "Siglo XVIII".

${ }^{13}$ Utilizo la edición facsimilar de la de ¿1495? impresa en Madrid (RAE), en 1951.

${ }^{14}$ A este respecto resulta de gran interés el cotejo de ambas obras llevado a cabo por Gloria Guerrero Ramos (1995: 147-156).

${ }^{15}$ En torno a esta evolución, véase especialmente desde la página 85 a la 97.
} 
Ahora bien, que el Vocabulario esté pensado desde el español, mientras que el Diccionario lo está desde el latín, no quiere decir que Nebrija no concibiese ambas obras como partes de un todo mayor, de un repertorio bidireccional, latín-español y españollatín ${ }^{16}$. Para Alvar Ezquerra (2002e: 136-137), tal concepción, en la que además del latín también cuenta el español (unida al hecho, ya mencionado, de considerarse a sí mismo como autoridad), justifica que el lexicógrafo sevillano no incluya ni las citas ni las autoridades tan habituales en los diccionarios monodireccionales de la época, destinados a la enseñanza del latín.

El Diccionario y el Vocabulario gozaron de un enorme éxito, a juzgar por las numerosas ediciones que conocieron (Guerrero Ramos 1995: 53-98), y muy pronto se tradujeron a otras lenguas (Acero Durántez 2003), pero la labor lexicográfica de Nebrija no fue entendida realmente por sus coetáneos (Alvar Ezquerra 2002e), por lo que tan solo supuso una "interrupción", aunque muy revolucionaria, en la tradición lexicográfica. Prueba de ello es la publicación en Sevilla, en 1499, del Vocabularium ecclesiasticum ${ }^{17}$ de Rodrigo Fernández de Santaella, que entronca, como el Universal vocabulario de Palecia, con la corriente lexicográfica medieval monolingüe latina a través de su fuente más inmediata, el Vocabulista ecclesiastico latino-volgare (Milán, 1480) ${ }^{18}$ del fraile Giovanni Bernardo da Savona ${ }^{19}$.

A diferencia de los diccionarios nebrisenses, el Vocabularium no va destinado al público en general, sino que tiene como objetivo facilitar a los religiosos la comprensión de los textos bíblicos y de las obras de autores cristianos. Esta "especialización" explica que el número de entradas recogido en el Vocabularium (en torno a unas 8000 ) sea bastante menor al de los diccionarios de Palencia y Nebrija. A estas entradas, como en el Universal vocabulario, le siguen numerosas informaciones: categoría gramatical, cantidad vocálica, definición o descripción enciclopédica, comentarios ortográficos y etimológicos, citas y ejemplos. Valgan artículos como los siguientes:

Aqueductus. ctus. ctui. el caño. que artificialmente es hecho para traer el agua a algun logar. affi como los caños que dizen de Carmona ${ }^{20}$ en feuilla. Tanbien fe dize aqueductus el curfo del agua por ellos. ij. Regum. ij. \& Judith. vij.

\footnotetext{
${ }^{16}$ De hecho, en un principio no se publicaron conjuntamente debido a dificultades económicas (Alvar Ezquerra 2002d: 19). Para José Perona el Diccionario y el Vocabulario forman parte de un proyecto más ambicioso, de un verdadero Thesaurus linguae latinae (1991: 212 y ss.).

${ }^{17}$ Utilizo el ejemplar que de esta edición se conserva en la Biblioteca Nacional de Madrid con la signatura I/1408.

${ }^{18}$ Según el Indice General degli Incunaboli delle Biblioteche d'Italia (1943-1981), a la edición de 1480 le siguen otras dos impresas en Milán $(1489,1495)$ y una tercera impresa en Florencia, en 1496. Las tres pudieron ser conocidas por Santaella, pues, su estancia en Italia abarca desde 1491 hasta 1496 (Hazañas y la Rúa 1909).

19 “Giovanni Bernardo utiliza muchos de los léxicos precedentes. Se ha creído ver en su diccionario ciertas concomitancias con las Cornucopiae sive linguae latinae commentarii de Niccoló Perotti y el La Summa quae vocatur Catholicon de Giovanni Balbi. Este último tiene como fuente, entre otras obras, el Elementarium doctrinae rudimentum por lo que es muy significativo que se hallen en el diccionario de Savonese referencias directas a Papias" (Medina Guerra 1996b: 158).

${ }^{20}$ El carácter enciclopedista del Vocabularium ecclesiasticum y de otros muchos repertorios posteriores, permite conocer aspectos importantes de la biografía de sus autores. En el caso de Fernández de Santaella, valgan, como
} 
Blande. aduerbium. qualitatis. Blandamente. genefis. 1. \& proberbiorum. xxiij.

Charistas. tatis. feminini generis. media correpta. con ch. enla primera fyllaba es efpecie de amor. f. el que. Es de dios. y del proximo. prouerbiorum. x. \&. j. ad corintios. xiij. y es la mayor de las tres virtudes teologales. y es greco. Si fe efcriue caritas fin. ch. fignifica careftia. y diriuafe de careo. res.

Famulus. li. mafculini generis. media correpta. por fieruo avnque otros quieren que en lengua de ofcos quiere decir fieruo. Dende tanbien fe dixo famula. le. por fierua. \& haze enel datiuo \& ablativo del plural famulis. \& tanbien famulabus mas vfitado entre los ecclefiafticos.

Mandragora. re. penultima correpta. femini generis. vna yerua cuya rayz tiene figura humana. Genefis. xxx. et. Canticorum. vij. \& fegun fant Aguftin el fructo defta es fermofo $\&$ olorofo. pero defabrido. dizen que es prouechofa para fazer enpreñar. En venecia ${ }^{21}$ vi muchal talef rayzef.

Olim. aduerbio. ideft mucho tiempo ha o ya mucho tiempo. ij. paffado. ij. ad Corinthios. xij. Jam olim Petri. ij. ideft eternalmente o del comienço del tiempo. fignifica tambien luengo tiempo por venir. Virgilius ${ }^{22}$.j. Eneyda. Tirias olim que verterte arces.

Planeta. te. media producta. la veftidura facerdotal que dize cafulla cafi cafilla. porque cubre todo. y en griego planeta fignifica cafilla. Item planeta es qualquier eftrella de fiete del zodiaco. que dizen planetas. fcilicet. Saturnus. Jupiter. Mars. Sol. Venus. Mercurios. Luna. por la cafulla es femenino. por la eftrella mafculino.

Potior. tiris. por vfar de cofas deffeadas o por confeguillas [...] fue otro tiempo dela tercera. agora es dela quarta conjugacion [...] Rige ablativo. Avnque alguna vez fe conftruye con genitivo. o con acusativo.

Rodrigo Fernández de Santaella se distancia así de la concisión y precisión de las equivalencias de Nebrija (Medina Guerra 1996a) y se convierte, como Palencia, en un eslabón más de la corriente lexicográfica de carácter enciclopedista iniciada en España por San Isidoro. Si bien, su fuente más inmediata no se halla en la lexicografía española, sino en la italiana, ya que se inspira, como se ha dicho, en el Vocabulista ecclesiastico latinovolgare del fraile Giovanni Bernardo da Savona (Medina Guerra 1996b y 2000) ${ }^{23}$. Obra que

ejemplos, los artículos “Carmon. nombre proprio de vn logar fuerte como es carmona mi logar natiuo. Ij. machabeorum. xij" o Mandragora. re, transcrito aquí mismo, en el que se alude a su estancia en Venecia. A este respecto, véase Medina Guerra (1994a).

${ }^{21}$ Como muchos hombres de letras o religión de su tiempo, Rodrigo Fernández de Santaella viajó a Italia ansioso por aprehender la latinidad clásica. Cursó estudios durante ocho años (1467-1475) en el colegio de San Clemente, en Bolonia, donde coincidió con su paisano Elio Antonio de Nebrija los tres primeros años.

${ }^{22}$ Las citas de los textos religiosos se combinan, esporádicamente, con referencia a obras de autores clásicos, en su mayoría de Virgilio. Este es, junto con Cicerón, uno de los autores latinos más citados por los lexicógrafos españoles.

${ }^{23}$ Ahora bien, el diccionario de Giovanni Bernardo no fue la única fuente del Vocabularium ecclesiasticum. Fernández de Santaella afirma en el prólogo de la edición de 1499 que su repertorio "[...] puede feruir muchas vezes quafi por concordancias. E por glofa delas cofas ecclefiafticas cuyos vocablos expone. para clerigos \& yglefias \& monafterios pobres. Mayormente que el Nicolao de lira egregio interprete \& otros glofadores dela fancta efcriptura comunmente exponen las fentencias della. E no vocablos prefuponiendo que de otra parte fe deue alcaçar la perfecta intelligencia dellos". A este respecto, véase Medina Guerra (2000). 
el sevillano revisa y mejora, pues no solo incorpora nuevas voces a la macroestructura del Vocabulista $^{24}$, sino que también aumenta el número de las citas y ejemplos, amplía las notas gramaticales o el número de acepciones:

Abba. fignifica patre. Syrum eft. habetur Marci capitulo. 14 (Giovanni Bernardo) ${ }^{25}$.

Abba vocablo hebreo es. y es tambien firo. Significa pater grece \& latine. en vulgar: padre. Marci. xiiij. ad romanos. viij. Nota que de abba fe dixo abbas el padre de los monjes que dizen abbad (Santaella).

Abdo. is. abdidi abditum. per abfcondere. mediam corripit cum pluribus compofitis a Do das. Primo Machabeorum primo (Giovanni Bernardo).

Abdo. dis. abdidi abditum. media correpta. con muchos compueftos de do das dedi. fignifica abfconder. Inde abditus abdita. tum. tanbien media correpta. fecreto o efcondido. Hymno. Verbum fupernum prodiens. Redens uicem pro abditif. i. por los males fecretos. es adiectiuo fubftantiuado. Et hymno. Urbs beata iherufalem abditis patentibus. i. moftrando o manifeftando los fecretos. algunos libros tienen aditis. y entonce fe exponga. i. las entradas patentes: o los fecretos manifeftados veelo en aditus tus. tui (Santaella).

Femur. oris. mediam corripit. \& hoc femen. inis. mediam corripit. fono le parte uergognofe circa le coxe. Judith. 9. Laurentius ualla inquit. Femora partem illam exteriorem fignificant. femina interiores mollioremque quę fe contingunt (Giovanni Bernardo).

Femur. moris. media correpta. \& femen. nis. neutri generis. fon los muflos. femen hallaras. Deuteronomio. xxviij. femur. judith. ix. Laurencio valla faze diferencia diziendo. femina fon los muflos dela parte de dentro que fe tocan. femora. la parte de fuera contraria a aquella. Otros dizen que femen. nis. es el mullo dela muger. E femur. moris. el del ombre (Santaella).

Precisamente la selección cuidadosa de $\operatorname{los}$ vocablos ${ }^{26}$ y las minuciosas indicaciones de las distintas acepciones con que estos aparecen en los pasajes bíblicos y en los autores eclesiásticos más leídos son dos de las claves del enorme éxito que tuvo el Vocabularium ecclesiasticum, siendo, además, la gran aportación de Rodrigo Fernández de Santaella a la lexicografía española.

\footnotetext{
${ }^{24}$ El Vocabularium duplica con creces el número de entradas recogidas en la obra de Giovanni Bernardo (Medina Guerra 1996b).

${ }^{25}$ Cito por el ejemplar que de la edición de Milán (1480) se conserva en la Biblioteca Nacional de Florencia con la signatura Guicc.6.7.23.

${ }^{26}$ Eso no quiere decir que, al igual que Giovanni Bernardo da Savona, Fernández de Santaella no incorpore voces del léxico común como, por ejemplo, Alapa. pe; Cibo. bas; Dirus. ra. rum; Focus. ci; Longus. ga. gum.
} 


\section{SIGLO XVI}

En el siglo XVI se siguen editando con gran éxito los repertorios de Nebrija. De este modo, entre 1503 y 1595, vieron la luz, según la catalogación realizada por Gloria Guerrero Ramos (1995: 60-79), cuarenta y tres ediciones de los diccionarios nebrisenses ${ }^{27}$.

Nebrija, además de revisar y adicionar algunas de las primeras de estas ediciones, continúa su labor lexicográfica, así, a él le debemos también, por ejemplo, como señala Manuel Alvar Ezquerra, “[...] un breve diccionario latino-español de carácter jurídico que contiene 600 entradas en latín con su correspondencia en español, los Latina vocabula ex iure ciuili in voces hispanienses interpreta" (2002c: 129) o el índice léxico de la Materia médica de Dioscórides (Alcalá, 1518), “[...] cuyo título es Lexicon illorum vocum quae ad mediacamentariam artem pertinerent, y puede ser considerado como un verdadero repertorio léxico, pues en él una gran porción de entradas griegas y latinas que remiten al texto tienen la correspondencia en español, 619 de las 1858 referencias, en las que se pueden encontrar 420 designaciones diferentes, a veces con variantes sobre las soluciones proporcionadas por Nebrija en sus otros diccionarios, lo cual nos muestra que Elio Antonio nunca abandonó las tareas sobre el léxico español" (2002c: 131).

Asimismo, el Vocabularium ecclesiasticum de Rodrigo Fernández de Santaella continuó publicándose y conoció al menos veintitrés ediciones ${ }^{28}$ entre 1503 y 1566 (Medina Guerra 1998a), año en que ve la luz en Salamanca el Lexicon ecclesiasticum de Diego Jiménez Arias. Siguiendo a Hazañas y la Rúa (1909), siempre he considerado a Jiménez Arias como un adicionador de Fernández de Santaella (Medina Guerra 1996c). La "Advertencia al que leyere" 29 de Martín David de la edición valenciana de 1685, las portadas de algunas ediciones del siglo XVIII ${ }^{30}$, las numerosas referencias a Fernández de Santaella que se

${ }^{27}$ De estas, solo tres (Granada, 1585; Granada, 1589 y Antequera, 1595) están corregidas por Juan López Serrano (Guerrero Ramos 1995).

${ }^{28}$ Solo contabilizo las ediciones de las que me consta que se conserva algún ejemplar: Sevilla, 1515; Zaragoza, 1523; Alcalá, 1527; Alcalá, 1529; Sevilla, 1529; Zaragoza, 1538; Alcalá, 1540; Salamanca, 1540; Zaragoza, 1540; Estella, 1546; Zaragoza, 1546; Salamanca, 1549; Zaragoza, 1549; Zaragoza, 1550; Medina del Campo, 1551; Toledo, 1552; Estella, 1555; Medina del Campo, 1555; Zaragoza, 1555; Salamanca, 1556; Toledo, 1556; Salamanca, 1561; Zaragoza, 1562. Hazañas y la Rúa (1909) cita también las de Zaragoza, 1508; Sevilla, 1528; Sevilla, 1550; Toledo, 1559; y Palau (1948-1977: V, n. ${ }^{\circ} 89736$, n. $^{\circ} 89743$ y n. ${ }^{\circ}$ 89754), Lión, 1503; Sevilla, 1539; Zaragoza, 1560 (Medina Guerra 1998a).

29 "La primera edicion de efte Vocabulario es de Roderico Ferdinando de Sancta Ella, año 1550, y aun defpues en otra, le añadio y corrigio el milmo en el de 1562. Y en el de 1565. el M. R. P. Fr. Diego Ximenez de Arias, de la Sagrada Orden de Predicadores, hizo de el nueva difpoficion, y forma, y le facò con titulo de Lexicon Ecclefiafticum, enriqueciendole de muchas vozes, con autoridades de la Sagrada Efcritura, comentos de muchos lugares de ella, y teftimonios de Santos Padres, Concilios, Decretos \&c. con mucha mas difufion, y energia que Rhoderico, y enmendando à efte muchas interpretaciones viciofas, que corrian en fu Vocabularium Ecclefiafticum [...]". Martín David yerra al fechar las ediciones del Vocabularium y del Lexicon a las que hace alusión, pues, como se ha dicho, la edición prínceps del Vocabularium ecclesiasticum es la impresa en Sevilla en 1499 y la primera con las mejoras de Jiménez Arias es la salmantina de 1566. Por lo que respecta a la edición de 1562 (véase la nota anterior), esta no pudo ser corregida por Santaella, ya que falleció en Sevilla el 20 de enero de 1509 (Hazañas y la Rúa 1909).

${ }^{30}$ Como las madrileñas de 1744, 1770 o 1789, que salen con el título de Vocabularium, seu Lexicon ecclesiasticum, y en las que se reconocen las autorías de Fernández de Santaella y Jiménez Arias desde la portada. 
encuentran a cada paso en el Lexicon (Medina Guerra 1996d), el cotejo de la macroestructura y microestructura de la edición de $1556^{31}$, corregida por Eustaquio Cervantes de Morales, y la de 1566 de Jiménez Arias eran argumentos más que suficientes para pensarlo de este modo. Sin embargo, investigaciones posteriores (Medina Guerra 2001a y 2001b) me hicieron ver que los numerosos cambios que se introducen en la redacción y presentación de los artículos convierten al Lexicon en una obra nueva, y a su autor, en un diccionarista que pone mucho de labor propia para mejorar la tradición lexicográfica. Con las mejoras realizadas por Jiménez Arias se publican diez ediciones más antes de que finalice el siglo, entre 1569 y $1597^{32}$ (Medina Guerra 1998a).

En 1587, ve la luz en Salamanca la primera y única edición del Dictionario de vocablos castellanos aplicados a la propiedad latina ${ }^{33}$ de Alonso Sánchez de la Ballesta ${ }^{34}$. Se trata de un repertorio español-latino de 10600 entradas, entre las que se encuentran numerosas formas pluriverbales, ya sean frases proverbiales, refranes o citas tomadas de autores latinos $^{35}$. De ahí que quizá la principal aportación de esta obra a la historia de la lexicografía española sea, como apuntó Samuel Gili Gaya, que “[...] contiene [...] numerosas frases que él explica por primera vez" (1960: XXIII). La importancia de los refranes y frases proverbiales es tal que en algunos repertorios bibliográficos, como el de Salvá y Mallén (1872: 237), se cataloga el Dictionario como una obra paremiológica ${ }^{36}$.

A pesar de ser un diccionario español-latín, no está concebido (a diferencia del Vocabulario de Nebrija) desde el español, sino desde el latín, y ello se refleja en la

\footnotetext{
${ }^{31}$ Esta edición, impresa en Salamanca en los talleres de "Ioannem Mariam da Terra Noua, \& Iacobum Archarium" y que lleva por título Dictionarium ecclesiasticum, es la primera que se publica con las correcciones de Eustaquio Cervantes de Morales, quien no escapa tampoco a las críticas de Jiménez Arias en 1566. Sin embargo, los ataques y alusiones negativas de Jiménez Arias no impidieron que el Vocabularium ecclesiasticum de Fernández de Santaella, tal como lo corrigió Cervantes de Morales, se reimprimiera en 1569 y 1572 en Alcalá de Henares, “[...] donde, acaso por su rivalidad con Salamanca, no fue bien recibido el libro de Ximénez Arias" (Hazaña y la Rúa 1909: 42).

${ }^{32}$ Una vez más, solo tengo en cuenta las ediciones de las que conozco algún ejemplar: Braga, 1569; Salamanca, 1572; Salamanca, 1579; Zaragoza, 1583; Salamanca, 1584; Salamanca, 1585; Lisboa, 1588; Zaragoza, 1588; Zaragoza, 1596; Barcelona, 1597.

${ }^{33}$ Utilizo el ejemplar que de esta edición se conserva en la Biblioteca Nacional de Madrid con la signatura $\mathrm{R} / 29806$.

${ }^{34}$ En opinión de Gonzalo Correas, se trata del seudónimo empleado por el padre Frómesta de San Agustín (Medina Guerra 1996e).

${ }^{35}$ Para Manuel Alvar Ezquerra, “[...] el origen de tantos elementos pluriverbales está en el fracaso de Nebrija. Como éste no incluyó citas o ejemplos en sus obras, la lexicografía posterior intenta remediar las carencias por todo los medios, y como ya existían no pocos latinos y latín-español con ejemplos y frases en latín es por lo que Sánchez de la Ballesta los pone en uno español-latín. No me explico de otro modo la estructura de su diccionario monodireccional" (2002d: 34).

${ }^{36}$ De hecho, su influencia se deja sentir en repertorios paremiológicos posteriores, como el Vocabulario de refranes y frases proverbiales de Gonzalo Correas o el "Alphabeto Tercero, que contiene la Razón y Declaración de algunos Refranes y Fórmulas Castellanas que dicen Hispanismos” del Diccionario etimológico de Francisco del Rosal (Medina Guerra 1998b).
} 
macroestructura, en la que se da cabida a combinaciones no lexicalizadas, seguramente, porque el autor no conoce el equivalente castellano de la voz latina:

Abertura en la tierra. Hiatus, us [...].

Abogado no muy auifado en los negocios de abogacía. Rabula, æ [...].

Aclarar el vendedor el precio que quiere por su mercadería. Indico. as [...].

Aparato folenne. Pompa, æ.

Aparato de guerra. Comparatio, is [...].

Cofa bufcada con regalos. Eblanditus. pro Plancio.

Cofa abreuiada. Epitome, es. Cicero. Non breuiarium.

Cofa de comer. Pulmentum, i. Tufculana. Non vtitur Cicero. Pulmentarium.

El que padece naufragio. Naufragus. de Inuentione.

El que advierte. Cautor, ris. pro Sextio.

El que ruega. Precator. Terentius in Heautontimorumeno.

El que haze hechizos. Veneficus. in Catilinam.

Lugar diputado para cantar. Odeum. penultima producta. libro. 4. epiftolæ ad Atticum.

Lugar adonde algo fe guarda, o recoge. Receptaculum. 2. de Natura Deorum.

Lugar pedragofo. Saxetum, i. pro lege Agraria.

Y de manera muy especial, en la microestructura, ya que, la mayoría de las veces, se nos indica, por ejemplo, la cantidad vocálica, el sinónimo griego o la contextualización, a través de citas de Terencio o Cicerón ${ }^{37}$, de la forma latina correspondiente a la entrada española, como puede apreciarse en los siguientes casos:

Aparador. Abacus, i. penultima correpta. in Verrem.

Autoridad. Authoritas. In Verrem. Item Apex. cis. de Senectute. Apex fenectutis eft authoritas.

Carril. Orbita, æ. Attico. Vt vix impreffam orbitam videre poflimus.

Concierto de palabras en la conftructión de alguna oración. Confecutio, nis. in Partitionibus. Græce Synthefis.

Faltar. Defit, cum datiuo. Terentius in Eunucho. \& in Hecyra. Nihil apud me tibi defieri patiar. \& Cicero. in Tufculanis.

Mil. Mille, \& conftituitur cum genitiuo. in Philippicis.

\footnotetext{
${ }^{37}$ Es tal la importancia que Sánchez de la Ballesta le confiere a Cicerón, que llega a indicar con absoluta claridad qué voces no son ciceronianas. Cicerón fue una autoridad muy citada en lexicografía y su obra sirvió de fuente casi exclusiva a algunos diccionarios, como el de Nizzoli, compendiado por Bartolomé Bravo.
} 
Ordenado. Compofitus. de Legibus. Inftructus. de Legibus. Conftitutus. de Oratote. Ordinatus, barbarum.

Parece obvio, pues, que para la redacción de su diccionario Sánchez de la Ballesta utilizó un diccionario latino-español, probablemente -dadas las concomitancias que presentan (Medina Guerra 1993)- pudiera tratarse de una edición con el español ${ }^{38}$ del Dictionarium plurilingüe de Ambrogio Calepino ${ }^{39}$, del que selecciona las informaciones que más le interesan, entre ellas, muchas citas de Terencio y Cicerón, eludiendo la referencia que el lexicógrafo bergamasco hace de obras de otros autores. Sirvan como ejemplos los artículos que siguen:

Ablandar. Delinio, is, iui. Cicero pro Milone. vt non modo virtute flecteret, fed etiam tribus fuis patrimonios delineret (Ballesta).

Delinio, is, ire [...] Hispanicum. Amanfar o ablandar [...] Cicero pro Milone, Vt non modo virtute flecteret, fed etiam tribus fuis patrimonios deliniret (Calepino) ${ }^{40}$.

Abaxar, Derrocar, Abatir. Deprimo, is, deprefsi, depreffum [...] Cicero antequam iret in exilium. Nam quem virtutis gloria cum fuma laude ad cælum extulit, eundem inimicorum inuidia indignifse oppreffum deprimit ad fupplicium [...] (Ballesta).

Deprimo, mis. penultima correpta. depreffi [...] Hispanicum. Abaxar y abatir, fuprimir [...] Cicero antequam iret in exilium, Nam quem virtutis gloria cum fumma laude ad cælum extulit, eudem inimicorum inuida indigniflime oppreffum deprimit ad fupplicium (Calepino).

Abreviado. Compendiarius. a, um. Cicerro. Officiorum. Socrates hac viam ad gloriam proximam. \& quafi compendiariam effe dicebat: fi quis id ageret, vt qualis haberi velit, talis effet. Hispanicum. Socrates defcubrió vn camino bien breue, pero bien cierto para la gloria, que fueflemos tales, quales deffeáuamos parecer (Ballesta).

Compendiarius, a, um [...] Hispanicum. Cofa da atajo\} Cicero libro. 2. Officiorum. Præclare, Socrates hac viam ad gloriam, \& quafi compendiariam dicebat effe, fiquis ita ageret, vt qualis haberi vellet, talis efret (Calepino).

El Dictionario se cierra con un "Index Adagiarum” de 20 páginas, en el que se recogen 1958 adagios latinos ${ }^{41}$, indicándose el autor del que se toma y la página del diccionario en que aparece para facilitar la consulta del lector. La mayoría de estos adagios proceden de los Adagiarum Chiliades de Erasmo, como reconoce Sánchez de la Ballesta en las palabras

${ }^{38}$ El diccionario de Ambrogio Calepino incluye por primera vez el español en 1559 (Gallina 1959 y Labarre 1975).

${ }^{39}$ Al que cita como autoridad en el Dictionario (Medina Guerra 1993: 380-381).

${ }^{40}$ Del diccionario de Calepino, utilizo un ejemplar de la edición de Lión de 1570 conservado en el Depto. de Filología Española I de la Facultad de Filosofía y Letras de la Universidad de Málaga.

${ }^{41}$ Estos adagios se traducen en el cuerpo del diccionario por diversas expresiones paremiológicas castellanas. Siguiendo la clasificación establecida por Gloria Corpas Pastor en el Manual de fraseología española (1996), Eva María González González (1998-1999) realiza una propuesta de sistematización de estas expresiones paremiológicas y las agrupa en locuciones, paremias y fórmulas rutinarias. A este respecto véase también Medina Guerra (1994b: 218-229). 
que dedica al lector: "[...] juzgue este trabajo por acertado para principio de lo que fe pretende, pudiendofe alcanzar con el lo mejor del lenguaje de Ciceron y Terencio, lo mas difficil de algunas fentencias fuyas, y entenderfe muchos refranes, afsi Latinos como Castellanos, y cafi todos los Adagios que con tanta diligencia junto Erasmo en sus Chiliadas [...]". Pero junto a Erasmo se cita a autores latinos y griegos, siendo los más nombrados Cicerón, Plutarco, Plauto, Aristófanes o Zenodoto (Medina Guerra 1993: 389).

Antes de que finalice el siglo, probablemente en torno a la década de los noventa ${ }^{42}$, se publica otro diccionario español-latín, el Thesaurus verborum ac phrasium ad orationem ex hispana latinam efficiendam \& locupletandam ${ }^{43}$ del jesuita Bartolomé Bravo. Este repertorio español-latín, dirigido a los estudiantes de la lengua latina, consta de unas 18000 entradas entre las que se encuentran, a pesar de ser un diccionario ciceroniano, como se dice en el prólogo, muchos términos eclesiásticos (Comunidad, o convento, Chriftiano, Diacono, Miffal, Monafterio de monges, Reliquias). También se catalogan, aunque en un número mucho menor que en el repertorio de Sánchez de la Ballesta, unidades pluriverbales como, por ejemplo, Mas vale al que Dios ayuda, que alque mucho madruga; Pienfa el ladron que todos fon de fu condición; Porfia mata venado que no valleftero canfado; Por miedo de paxaros, no dexéis de fembrar mijo; Por mucho pan, nunca mal año ${ }^{44}$. En cualquier caso, la presentación de los materiales del Thesaurus es mucho más moderna que la del Dictionario de Sánchez de la Ballesta. En líneas generales, hay en Bartolomé Bravo, como en Nebrija, un dominio casi absoluto de las equivalencias. Así, del Thesaurus están ausentes las informaciones referentes a la voz latina que encontrábamos a cada paso en el repertorio de Sánchez de la Ballesta. Los artículos del diccionario de Bravo se limitan, en la mayoría de los casos, a la entrada española y al sinónimo o sinónimos latinos, lo que le convierte en deudor de la corriente lexicográfica iniciada por Antonio de Nebrija un siglo antes (Medina Guerra 1997) ${ }^{45}$. Sirvan de ejemplos los artículos siguientes:

\footnotetext{
${ }^{42}$ Como ya señalé en otra ocasión (1994b: 358), la primera edición del Thesaurus es, según Antonio Palau y Dulcet (1948-1977: II, n. ${ }^{\circ}$ 34617), la impresa en Pamplona en 1590; sin embargo, Antonio Pérez Goyena (1947: n. ${ }^{\circ}$ 167) afirma que "[...] ni los bibliógrafos jesuitas ni los navarros tienen noticias de semejante impresión". A juzgar por la aprobación de la edición de Palma de 1607, en la que se señala a esta de 1607 como la cuarta edición, el Thesaurus debió conocer al menos tres ediciones más con anterioridad: la zaragozana de 1601 (se conserva un ejemplar en la Biblioteca Pública Episcopal del Seminario de Barcelona con la signatura R. 80.208), la valenciana de 1606 (en la Biblioteca Nacional de Lisboa con la signatura L.4262V) y la edición prínceps, que bien podría ser la zaragozana de 1597, de la que no conozco ningún ejemplar, pero la citan, entre otros, Antonio (1783-1788: I, 189), Cejador (1972: III, 366), Menéndez y Pelayo (1902: I, CCLXXX) y Palau (1948-1977: II, n. ${ }^{\circ} 34618$ ); o la salmantina de 1599, citada solo por Palau (1948-1977: II, n. $\left.{ }^{\circ} 34619\right)$, pero que el bibliófilo catalán describe más detalladamente que la de 1597.

${ }^{43}$ Utilizo el ejemplar de la Biblioteca Nacional de Madrid (R/24280) de la edición de Palma de 1607.

${ }^{44}$ Ahora bien, lo frecuente es que este tipo de construcciones no tenga, a diferencia del Dictionario de Sánchez de la Ballesta, una entrada propia, sirviendo, en la mayoría de los casos, para contextualizar la voz de la entrada, por ejemplo, bajo Blanco, o feñuelo se encuentran Dar en el blanco o Tirar al blanco y bajo Cencerro, $A$ cencerros atapados.

${ }^{45} \mathrm{Su}$ fuente no es el Compendium de Mario Nizzoli como, siguiendo a Marcelino Menéndez y Pelayo (1902), han afirmado, entre otros, Julio Cejador (1972) o Antonio Palau y Dulcet (1948-1977: II, n. ${ }^{\circ}$ 34640-34644). Entre las ediciones del Thesaurus, Menéndez y Pelayo cita dos ediciones del Compendium, obra también de Bravo (la vallisoletana de 1627 y la complutense de 1672); ediciones a las que debe referirse cuando afirma que en algunas
} 
Abraço. Amplexus, us. complexus, us.

Adalid o guía. Dux, cis.

Baile, o dança. faltatio, onis.

Buey. bos, vis.

Floxo, no apretado. Laxus, a, um.

Lagar, do pifan la uua. lacus, cus.

Laurel. laurus, i.

Librero, que vende libros. bibliopola, æ.

Librero, que efcrive libros. librarius, ii.

Mulo. Mulus, i.

Res, cabeza de ganado. pecus. udis.

\section{SIGLO XVII}

Se siguen publicando con éxito los diccionarios de Nebrija con las mejoras de López Serrano $^{46}$ y el Lexicon ecclesiasticum de Jiménez Arias ${ }^{47}$, y ven la luz numerosas ediciones del Thesaurus ${ }^{48}$ de Bravo; pero la gran aportación de este siglo a la historia de los diccionarios con el latín y el español es la edición en Valladolid en 1619 (doce años

salidas del Thesaurus se declara que es un resumen de la obra de Nizzoli. Nizzoli es, en efecto, la fuente del diccionario latino-español de Bartolomé Bravo y así lo declara su autor desde el título (Compendium Marii Nizolii sive Thesauri Marci Tulii Cicerones, quo tum verba, tum variae cuiusque formulae, ac locuciones, quipus idem usus est, continentur hispano idiomote singulis verbis ad scripto), pero no del diccionario español-latín, del Thesaurus. Para el cotejo del Thesaurus con el Compendium de Nizzoli, véase Medina Guerra (1997).

${ }^{46}$ Gloria Guerrero (1995) cita las siguientes ediciones: Antequera, 1600; Madrid, 1615; Madrid, 1622; Madrid, 1631; Madrid, 1638-1640; Madrid, 1645; Madrid, 1649-1650; Lugduni, 1655; Madrid, 1656; Granada, 1658; Madrid, 1665; Madrid (Juan García Infanzón), 1674; Madrid (Tipografía regia), 1674; Madrid, 1681; Madrid, 1683

${ }^{47}$ Conozco ejemplares de las siguientes: Medina del Campo, 1601; Zaragoza, 1601; Barcelona, 1608; Barcelona 1613; Salamanca, 1613; Barcelona, 1618; Valencia, 1621; Zaragoza, 1621; Zaragoza, 1625; Valladolid, 1628; Barcelona, 1631; Barcelona, 1642; Zaragoza, 1644; Madrid, 1650; Madrid, 1659; Valencia, 1685; Valencia, 1697; Barcelona, 1697 (Medina Guerra 1998a).

${ }^{48}$ Me consta ejemplares de estas: Zaragoza, 1601; Valencia, 1606; Palma, 1607; Zaragoza, 1607; Valencia, 1608; Pamplona, 1610; Zaragoza, 1610; Madrid, 1611; Pamplona, 1612; Madrid, 1618; Valladolid, 1618; Madrid, 1619; Valencia (Felipe Mey), 1621; Valencia (Jerónimo Vilagras), 1621; Barcelona, 1626; Barcelona, 1627-1628; Zaragoza, 1628 (erróneamente Gloria Guerrero [1995: 81], siguiendo a Palau [1948-1977: X, n. ${ }^{\circ}$ 189200], cita esta edición entre las de los diccionarios de Nebrija); Barcelona, 1635; Zaragoza, 1640; Madrid, 1643; Madrid, 1644; Valladolid, 1645; Madrid, 1648; Madrid, 1652; Valencia, 1652; Valencia, 1654; Valladolid, 1654; Valladolid, 1662; Valladolid, 1665; Madrid (Tipografía Regia), 1666; Madrid (Mateo de Espinosa y Arteaga), 1666; Valencia, 1666; Valencia, 1672; Madrid, 1679; Madrid (Francisco Hernández), 1688; Madrid (Juan García Infanzón), 1688; Zaragoza, 1688; Valladolid, 1693; Barcelona, 1697; Valencia (Iván Bautista Ravanals), 1698; Valencia (Jacobo de Bordazar), 1698. La mayoría de estas ediciones están descritas en Medina Guerra (1994b: 567-611). Véase también el Catálogo colectivo del patrimonio bibliográfico español. 
después de la muerte de su autor ${ }^{49}$ del Compendium Marii Nizolii sive Thesauri Marci Tulii Ciceronis, quo tum verba, tum variae cuiusque formulae, ac locuciones, quibus idem usus est, continentur hispano idiomate singulis verbis ad scripto ${ }^{50}$ de Bartolomé Bravo, gracias a los esfuerzos de su sobrino, Pedro Bravo, miembro también de la Compañía de Jesús ${ }^{51}$.

El Compendium, como el Thesaurus, está dirigido a los jóvenes que estudian latín. Bartolomé Bravo conoce como profesor la necesidad de utilizar en las aulas obras que contribuyan a difundir la elegancia y pureza de la lengua latina entre la juventud. En el prólogo del Compendium exalta la labor realizada, entre otros, por Robert Estienne, Ambrogio Calepino, Mario Nizzoli, etc., sin embargo, estas obras fundamentales para el estudio de la lengua latina son incómodas de manejar debido a sus grandes dimensiones, por lo que su objetivo será realizar una obra de reducido tamaño que encierre lo mejor de la lengua latina. Con este fin, según se nos indica en el título y en el prólogo, toma como punto de partida la obra de Nizzoli, de la que probablemente utilizaría una edición plurilingüe inspirada en el Dictionarium de Calepino ${ }^{52}$.

Este diccionario latín-español recoge unas 14000 entradas, entre las que se encuentra un reducido número de nombres propios y construcciones pluriverbales, que pasan desapercibidas en la macroestructura del diccionario. A estas, le siguen las distintas acepciones de la voz, delimitadas en función del contexto en el que aparece, siendo frecuente que Bravo indique sus posibles usos metafóricos:

Aceruatim. penultima producta. A montes. Metaphorice Samaciamente Sin orden. Aceruatim multa dicere.

\footnotetext{
${ }^{49}$ Sabemos que Bravo murió en Medina del Campo (Valladolid) en 1607.

${ }^{50}$ Bravo, al igual que Nebrija, acomete la tarea de confeccionar dos diccionarios, uno español-latino, el Thesaurus, y otro latino-español, el Compendium, y, como el lexicógrafo sevillano, no se limita a un simple trasvase de información de uno a otro repertorio. Para empezar, parte de fuentes diferentes y, por tanto, las diferencias son obvias: 1) el número de entradas en el Thesarus es superior al del Compendium; 2) en la macroestructura del Compendium no se hallan muchos de los equivalentes latinos de las entradas españolas del Thesaurus y 3) en ocasiones, los equivalentes latinos del Thesaurus se recogen en el Compendium con otro sentido, o lo que es lo mismo, no siempre las entradas españolas del Thesaurus coinciden con las traducciones de las entradas latinas del Compendium (Medina Guerra 1994b: 411-418).

${ }^{51}$ Véase a este respecto la "Licencia"de la edición vallisoletana de 1619, firmada en Valladolid el 2 de mayo de ese año por Diego de Sosa en la que se afirma lo siguiente: "Por quanto por parte de vos Pedio Brauo Religioso de la Compañía de Iesus, nos fue fecha relacion, que por nos se auia dado licencia al Padre Bartolomé Brauo, vuestro tio, difunto Religioso que fue de la dicha Compañía, para que pudiesse imprimir vn libro por el compuesto, intitulado, Compendium M. Nizolii, siue Thesauri Cicerones, y priuilegio por diez años, y por auer muerto el suso dicho no auia podido tener efecto la dicha impression [...] Por la qual os damos licencia, y facultad para que por tiempo de diez años primeros siguientes, vos ò la persona que vuestro poder huuiere, y no otro alguno podays imprimir, y vender el dicho libro [...]". Utilizo el ejemplar conservado en la Biblioteca General de la Universidad de Sevilla con la signatura 148/60.

${ }^{52}$ Al menos a partir de la edición de 1671, corregida y aumentada por Pedro de Salas, se reconoce la importancia del Dictionarium de Ambrogio Calepino, cuyo nombre pasa a ocupar un lugar relevante en la portada por lo que el Compendium fue conocido popularmente como el Calepino de Salas.
} 
Alte. En Alto. Alte extollere manum, fe a terra altius extollere. De alto. Alte cadere. Hondo. Sulcum altè imprimere.

Conftituo. is. ui utum. Poner en algun lugar. crucem alicui conftituere. Ante illius pedes conftitutus. Determinar, ordenar. conftitutum mihi eft $[\ldots]$.

Lumen, inis. lumbre, o luz. Lumen alicui preferre. lumen de fuo lumine accendere. Tabulas bene pictas in bono lumine collocare. Ventana. Ædium lumina. Dia Secundo lumine. Ojos. lumina amittere.

Via, æ. Camino, calle [...] Metaphorice Modo, manera, traça. Hæcres duplicem habet docendi viam $[\ldots]$.

Como puede verse en los artículos anteriores, la intención didáctica con la que nace el Compendium se aprecia especialmente en la contextualización de la voz latina de la entrada a modo de ejemplo. No se especifica el autor del que se toman estos ejemplos, pues -salvo muy extrañas excepciones- el modelo, al igual que en el Thesaurus, es Marco Tulio Cicerón. En cambio, en el apéndice final, "Verba quam plvrima quæ in cicerones scriptum desiderantvr, a varijs scriptoribus collecta" ${ }^{53}$, se señala minuciosamente de qué autor ${ }^{54}$ se toma el vocablo latino de la entrada:

Bafium, ij. Befo. Terentius.

Gulofus, a, um. Comedor, golofo. Martialis.

Pulpitum, i. penultima correpta. Tablado para reprefentar, plinius púlpito, Suetonius.

Rauis. is. Ronquera. Plautus.

Vetres, is. Berraco Horatius.

Al igual que el Thesaurus, el Compendium gozó de un gran éxito ${ }^{55}$ y siguió publicándose con las mejoras y correcciones de adicionadores de la talla del también jesuita Pedro de Salas, a quien le debemos cambios significativos en la macroestructura y microestructura de ambos diccionarios. La primera edición del Thesaurus corregida por Salas parece ser la impresa en Valladolid en $1645^{56}$ con el título Thesavrrus hispanolatinvs

\footnotetext{
${ }^{53}$ En ediciones posteriores, como en las corregidas por Pedro de Salas, este apéndice será reemplazado por una lista de voces sacras ("Nomina, et verba sacra, quórum difficilis ufus, \& significatio apud literas, \& scriptores sacros reperitur; breviter expofita, \& ex Latino in Hifpanum fermonem translata") y una de voces hebreas ("Plurimæ voces hebreæ in latinum, et hispanum sermonem, translatæ"). Estas listas de voces sagradas y hebreas son el punto de partida de las adiciones de Lama Cubero al Vocabularium, seu Lexicon ecclesiasticum de Rodrigo Fernández de Santaella y Diego Jiménez Arias. Véase lo expuesto a este respecto bajo el epígrafe "Siglo XVIII".

54 Entre los autores citados se encuentran: Virgilio, Terencio, Plinio, Plauto, Quintiliano, Varrón, Horacio, Suetonio, Marcial, Ovidio, etc.

${ }^{55}$ Además de la impresa en Valladolid en 1619, en este siglo, vieron la luz las siguientes ediciones: Valladolid, 1641; Valladolid, 1657; Madrid, 1668; Valladolid, 1671; Alcalá, 1672; Burgos, 1682; Madrid, 1695. Una vez más solo recojo las ediciones de las que conozco algún ejemplar (Medina Guerra 1994b: 660-670).

${ }^{56}$ Menéndez y Pelayo (1902) cita como la primera edición del Thesaurus de Salas la impresa en Valladolid en 1643. No tengo noticias de que se conserve ningún ejemplar en las bibliotecas españolas. De la edición vallisoletana de 1645 del Thesaurus he manejado el ejemplar de la Biblioteca General de la Universidad de Salamanca (BG/34265).
} 
vtrivsque linguce dives opvm; la primera del Compendium, la vallisoletana de $1671^{57}$ con el título Compendium latino hispanum, vtrivsque linguce veluti lvmen qvo Calepini ${ }^{58}$, Thesavri Enrici Stephani, Antonij Nebrisensis, Nizolij, P. Bartholomoi Bravo, atque omnium optimce notce authorum labores, \& lucubraciones.

En $1679^{59}$, otro jesuita, Baltasar Henríquez, publica en Madrid, en la imprenta de Juan García Infazón, el Thesaurus vtrivsque linguae hispanae et latinae, omnivm correctissimvs. Para Samuel Gili Gaya, se trata de una adición al diccionario hispano-latino de Nebrija de considerable importancia "[...] no tanto por las palabras nuevas que registra como por el esmero y reelaboración de las equivalencias latina" (1960: XX), sin embargo, esta obra parece guardar también ciertas semejanzas con las ediciones del Thesaurus de Bravo corregidas por Salas (Medina Guerra 1994b: 369-374) ${ }^{60}$. Así, el Thesaurus de Henríquez sigue siendo, como el de Bravo, un diccionario principalmente ciceroniano, si bien su autor no duda en citar junto a Cicerón a otros escritores latinos como César, Salustio o Tito Livio $^{61}$. De este modo, la incorporación sistemática de voces no ciceronianas se convierte en la contribución más importante de Baltasar Henríquez a esta cadena lexicográfica.

\section{SIGLO XVIII}

Al igual que en los siglos precedentes continúan editándose los repertorios de Nebrija con las mejoras de López Serrano ${ }^{62}$, López de Rubiños ${ }^{63}$ y Eugenio Ceballos ${ }^{64}$, y el Lexicon ecclesiasticum de Jiménez Arias ${ }^{65}$; pero la fama del Thesaurus $^{66}$ y del Compendium $^{67}$ de

\footnotetext{
${ }^{57}$ Es la primera edición del Compendium de Salas, según Palau (1948-1977: XVII, n. $\left.{ }^{\text { }} 286149\right)$. Se conserva un ejemplar en la Biblioteca General de la Universidad de Barcelona (XVII-1405).

${ }^{58}$ Véase la nota 52.

${ }^{59}$ Antonio Palau (1948-1977: VI, n. ${ }^{\circ}$ 113014) y Maurizio Fabbri (1979: n. $\left.{ }^{\circ} 1551\right)$ citan una edición de Heríquez impresa en Madrid por Juan García Infazón en 1670, de la que no conozco ningún ejemplar. Es curioso que ni Palau ni Fabbri hagan mención de la edición de 1679 de la que se conservan varios ejemplares en distintas bibliotecas españolas, por ejemplo, en la Biblioteca Nacional de Madrid con la signatura 3/4655, que es el que manejo.

${ }^{60}$ Es muy probable que la influencia de Nebrija llegase indirectamente a través de Bravo y sus seguidores, pues, como ya se ha dicho, el jesuita es deudor de la corriente lexicográfica iniciada por el andaluz.

${ }^{61}$ Véase a este respecto la breve advertencia al lector que precede en la edición de 1679 al repertorio lexicográfico.

${ }^{62}$ Gloria Guerrero Ramos (1995) cita las siguientes ediciones: Madrid, 1724; Madrid, 1729; Madrid, 1733; Sevilla, 1734-1735; Madrid, 1751; Madrid, 1758; Madrid, 1764.

${ }^{63}$ Como, por ejemplo, Madrid, 1754; Madrid, 1756; Madrid, 1778; Madrid, 1790 (Guerrero Ramos 1995).

${ }^{64}$ Entre ellas, Alcalá, 1762; Madrid, 1771; Madrid, 1776; Madrid, 1780; Madrid, 1784; Madrid, 1789; Alcalá 1792 (Guerrero Ramos 1995).

${ }^{65}$ Conozco ejemplares de las siguientes ediciones: Barcelona, 1702; Barcelona, 1713; Madrid, 1720; Pamplona, 1722; Barcelona, 1728; Madrid, 1728; Barcelona (Paulo Campins), 1739; Barcelona (Juan Piferrer), 1739; Madrid, 1744; Barcelona, 1750; Vich, 1756; Barcelona, 1762; Barcelona, 1763; Madrid, 1770; Madrid, 1774; Madrid, 1789; Gerona, 1792; Barcelona, 1798 (véase Medina Guerra 1998a).
} 
Salas fue tal, que Juan Lama Cubero ${ }^{68}$, cuando corrige el repertorio de Arias en 1739, incorpora un apéndice tras el diccionario con el encabezamiento: "Adiciones al Vocabularium Eclesiastico, segun la mente del doctisimo Padre Salas, de la Compañia de Jesus. Por D. Juan Lama Cubero, Preceptor de Letras Humanas, y Examinador en el Tribunal de la Nunciatura". Estas adiciones consisten en 1682 entradas, a las que les sigue el equivalente español sin precisar, salvo en contadas ocasiones, el pasaje bíblico o el texto eclesiástico en que se emplean. Todas ellas se hallan en los apéndices de voces sagradas y hebreas recogidas al final del Compendium ${ }^{69}$. Lama Cubero se limita, pues, a copiar estas informaciones con cuidado de omitir las voces que ya estaban catalogadas en el Lexicon ecclesiasticum. Su intención, por tanto, no es otra que la de revitalizar el Lexicon y evitar que fuese eclipsado por el enorme éxito del que ya entonces gozaba el Compendium.

A Salas sigue también el jesuita Valeriano Requejo en sus correcciones y adiciones al Thesaurus, pero sin dejar de poner labor propia. La primera edición con las mejoras de Requejo parece ser la salmantina de 1729, que se publica con el título Thesaurus hispanolatinus utriusque linguce verbis, et phrasibus abundans. Este nombre es sustituido en el siglo siguiente por el de Tesauro de Requejo reformado en las ediciones madrileñas de 1828 y 1838, y por el Nuevo Tesauro o sea Diccionario español-latino en la salida también madrileña de 1860 .

Ahora bien, la buena acogida por parte del público de estos diccionarios no impide que en la última década del siglo, en $1793^{70}$, en Madrid, irrumpa con fuerza el Diccionario

${ }^{66}$ En este siglo el Thesaurus conoció numerosas ediciones y, al menos a partir de 1729, fue corregido y adicionado por Valeriano Requejo: Madrid, 1701; Valencia, 1705; Barcelona, 1714; Barcelona, 1716; Barcelona, 1717; Madrid, 1717; Madrid, 1724; Pamplona, 1724; Pamplona, 1727; Madrid, 1729; Salamanca, 1729; Zaragoza, 1743; Madrid, 1746; Madrid, 1753; Barcelona, 1757; Madrid, 1757; Villagarcía, 1761; Villagarcía, 1763; Madrid, 1766; Madrid, 1770; Madrid, 1775; Madrid, 1777; Madrid, 1781; Madrid, 1783; Madrid, 1785; Madrid, 1787; Barcelona, 1791; Madrid, 1794; Barcelona, 1795; Alcalá 1797. La mayoría de estas ediciones están descritas en Medina Guerra 1994b: 611-640. Véase también el Catálogo colectivo del patrimonio bibliográfico español.

${ }^{67}$ El Compendium ve la luz en las siguientes ocasiones: Madrid, 1709; Amberes, 1714; Amberes, 1724; Madrid, 1726; Valladolid, 1726; Amberes, 1732; Amberes, 1740; Valladolid, 1743; Barcelona, 1748; Valladolid, 1756; Pamplona, 1761; Valladolid, 1761; Madrid, 1762; Madrid, 1771; Madrid, 1775; Madrid, 1779; Madrid (Hilario Santos Alonso), 1782; Madrid (Román), 1782; Madrid, 1784; Madrid, 1785; Madrid, 1787; Alcalá, 1795; Barcelona, 1795; Madrid, 1796; Barcelona, 1798; Madrid, 1799 (solo cito las ediciones de las que me consta se conserva algún ejemplar). La mayoría de estas ediciones están descritas en Medina Guerra (1994b: 671-690). Véase también el Catálogo colectivo del patrimonio bibliográfico español.

${ }^{68}$ Entre las ediciones corregidas por Lama Cubero se encuentran las siguientes: Barcelona (Paulo Campins), 1739; Barcelona (Juan Piferrer), 1739; Madrid, 1744; Madrid, 1770; Madrid, 1776; Madrid, 1789.

${ }^{69}$ Véase la nota 53.

${ }^{70}$ Como es sabido, en este año vio la luz el cuarto y último volumen del Diccionario castellano con las voces de ciencias $y$ artes $y$ sus correspondencias en las tres lenguas francesa, latina e italiana (1786-1793) del jesuita Esteban de Terreros y Pando. En este volumen se recogen "[...] unos apéndices que hacen las veces de tres diccionarios: italiano-español (que contiene unas 35000 entradas), francés-español (aproximadamente 45000 ) y latín-español (alrededor de 26 000)" (García Platero 2003: 266). Según advierte su editor, Miguel de Manuel y Rodríguez (Álvarez de Miranda 1992: 561-562), “[...] la mayor utilidad de este tomo consiste en que se preste auxilio á los Españoles estudiosos para la inteligencia de los libros técnicos de Ciencias y Artes que esten escritos en alguna de las tres lenguas contenidas en él, me he contentado con expresar desnudamente las correspondencias castellanas sin explicacion alguna de estas mismas: porque si á conseqüencia de esta expresión se hubiese 
universal latino-español de Manuel de Valbuena, quien, en el prólogo, critica en varias ocasiones, precisamente, la labor realizada por López de Rubiños y Salas:

Si el Padre Rubiños, adicionador del Diccionario de Nebrija, hubiera tenido mejor eleccion en muchos egenplos y sus interpretaciones, si no hubiera dejado un gran número de voces con la esplicacion ó definición en latin, y si hubiera adoptado un método más útil y sencillo en la formación de su Diccionario Latino-Español (porque no hablo del Español-Latino), podría suplir las faltas de los anteriores, por ser mas completo que ellos; pero por razon de los defectos insinuados, la falta de autoridad que conpruebe sus voces y frases, y las vulgaridades que adoptó en muchas de sus traducciones, está todavía muy lejos de satisfacer á los deseos de los inteligentes.

$[\ldots]$

En toda la obra se sigue el órden riguroso del alfabeto, cuyo método, ademas de dar mas facilidad al uso del Diccionario, está menos espuesto á equivocaciones, que el de poner los compuestos bajo el artículo de los sinples, y los derivados bajo del de las raices de que se forman: que es uno de los defectos mas considerables y embarazosos de los Diccionarios de Salas y Rubiños. Este método es la causa de que al hacer cotejo entre algunos artículos de mi Diccionario con los que acabo de nonbrar, parece á primera vista que estan mas llenos, y bien desenpeñados en ellos; pero examinándolos con atención, quitando las frases enteramente parecidas, y las menos latinas como inútiles, y separando las que no son de aquel lugar, por pertenecer á otro artículo, se hallará que el nuevo hace mucha ventaja á los anteriores en la abundancia y elección de los ejemplos ${ }^{71}$ (pp. VII-IX).

Este diccionario ${ }^{72}$ de más de 55000 entradas toma como modelo, según reconoce su autor, a los de Forcellini y Jean Boudot. La intención de Valbuena parece ser semejante a la de Bravo en su Compendium de Mario Nizzoli, esto es, pretende hacer más manejable el diccionario que considera de mayor utilidad para los jóvenes que estudian latín, que para él no es otro que el voluminoso diccionario de Forcellini ${ }^{73}$. Con este fin, abrevia las

explicado el término en cada Diccionario, seria una repetición fastidiosa, hubiera crecido considerablemente la edicion, y lo que ahora es un tomo, aunque bastante voluminoso, tal vez pasaria de dos ó tres de igual volumen. Para el que no entienda todo el significado de la voz castellana es fácil el recurso al Diccionario grande, donde la hallará con toda la explicacion que puede desear, principalmente por lo que mira á intrumentos de Oficios y Artes, y de lo demas que es poco sabido de los que no son artitas y facultativos de profesion. El mismo deseo de que no abultase demasiado este tomo, ó que no pasase á otro, me ha obligado á poner en tres colunas el Vocabulario Latino, teniendo dos únicamente los demas; y así espero que por esta razon de conveniencia no se criticará la deformidad que en esta parte pueda notarse" (p. III; cito por la edición facsimilar publicada en Madrid, Arco/Libros, 1987).

${ }^{71}$ Utilizo el ejemplar que de la segunda edición de 1808 (Madrid) se conserva en la Biblioteca de Filosofía y Letras de la Universidad de Málaga con la signatura a/1858.

${ }^{72}$ Tras él se recoge el apéndice "Diferencias de las voces latinas que parecen sinónimas y de las que se contraponen", de unas 1500 entradas.

73 "De suerte, que à excepción de algunos ejemplos muy raros, de algunas acepciones y frases, ó no bien comprobadas, ó de uso muy antiguo, y de algunos puntos de erudición, que me han parecido menos necesarios, viene á ser mi Diccionario el de Forcelini, sin las citas que le hacen tan voluminoso, reducidos los lugares de los autores á las meras frases, y abreviadas lo mas que ha sido posible sus definiciones é interpretaciones; pero de voces no falta ninguna, como no haya sido por descuido. Reducido asi este escelente Diccionario á un conpendio, 
definiciones o interpretaciones y elimina las citas, si bien, como puede verse en los artículos que transcribo más abajo, se indica la autoridad por medio de abreviaturas ${ }^{74}$ :

Condurdum, i. n. Plin. Planta que florece en el solsticio del estío con flores encarnadas, que traida al cuello cura la papera.

Expulsus, a, um. part. de Expello. Cic. Espulso, echado, arrojado.

Gabriel, ēlis. m. Ecles. Gabriel, nombre de un Angel, que quiere decir fuerza de Dios, el honbre de Dios.

Inuxōrus, a, um. Tert. El que no es casado, celibato, soltero.

Măcěo, ěs, cui, ère. n. Plaut. Enmagrecer, enflaquecer, ponerse flaco, enjuto de carnes. Ossa atque pellis est, ita cura macet. Plaut. Tan consumido le tienen las pesadumbres, que no tiene mas que huesos y pellejo.

Pacuvius, ii. m. Cic. Pacuvio, poeta latino de Brindir, que nació en el siglo VI de Roma, y escribió tragedias con mal estilo, segun dice Ciceron en el Bruto, y se dedicó tambien á la pintura: Plinio, lib. 35, cap. 4, hace mencion de un quadro suyo en el tenplo de Hercules.

En cualquier caso, la búsqueda de brevedad no implica que no se recojan todas las informaciones que se consideren necesarias para el correcto uso e interpretación de la voz de la entrada ${ }^{75}$ :

Hepthēmŭmĕris, is. f. Serv. Heptemimeris, especie de cesura en los versos exametros, que contiene tres pies y una sílaba que finaliza la diccion, y se hace larga por licencia

no por eso dejan de tener todas las voces y frases su autoridad, y las diferentes acepciones en que han sido usadas por los autores latinos con sus equivalentes castellanos, como podrá observarse en cada artículo; y si faltan algunas, es porque ó no las hay, ó porque la significación y construccion de la voz no admite en su uso dificultad alguna" (p. VIII). Sin embargo, y a pesar de estas palabras de Valbuena, en algunas de las ediciones corregidas por Vicente Salvá se advierte que el Diccionario universal latino-español no está “[...] sacado del de Forcellini, como [Valbuena] lo pretende en su prólogo, sino traducido servilmente del compuesto por Boudot, á quien tiene el cuidado de no mencionar mas que por incidente, para decirnos que ha adoptado su sistema de poner en abreviatura los nombres de los autores que cita (lo cual ni es una gran invencion, ni se debe à Mr. Blondeau, verdadero autor del diccionario que salió á nombre de Boudot) y que ha añadido algunas definiciones en vocablos en que este las omite".

${ }^{74}$ También se catalogan voces que carecen de autoridad, como, por ejemplo, ciertos nombres geográficos o voces propias de distintas "artes y facultades": Gaberus, i. $m$. El Gabe, rio de Francia; Lappōnia, a. $f$. La Laponia, pais grande septentrional de Europa; Pharmăcia, a. $f$. La purgación por los medicamentos; Pharmăcītes, is. com. Lo que entra en la composición de los medicamentos. Asimismo, se incorporan unidades de las que no se da el equivalente español. Valgan los siguientes ejemplos: Bucerius, a, um. Lucr. y; Herōdio, ōnis. m. y; Măre Syriacum, ó; Mūlleǒlus, a, um. Tert. dim. de.

75 "En todas las voces se explican con abreviaturas sus accidentes y propiedades; se nota la cantidad de sus sílabas, á lo menos las dudosas; se pone en castellano su significado propio; se añaden equivalentes para mayor inteligencia, y aun otras voces que parecen sinónimas; se siguen las diferentes acepciones, y á estas las frases quando la voz tiene varias construcciones. A veces se observará que no hay frases correspondiente á todas las diversas acepciones puestas de la voz, y la razon de esto es, ó por ser claro el uso de ella en aquellas acepciones de que falte ejemplo, ó porque se ha tenido particular cuidado en la brevedad; y asi solo se han puesto los ejemplos en que hay alguna particularidad de régimen ó construccion gramatical”. 
poética, aunque sea por su naturaleza breve: v.g. Congredi-or, fe-sacra pa-ter, \& concipefodus.

Irrŏgo, ās, āvi, ātum, āre. a. Cic. Imponer, establecer. IInponer, establecer. IPedir el establecimiento ó ratificado de. IQuint. Acordar, conceder. Irrogare legem alicui Cic. Pedir que se establezca una ley contra alguno. - Pœnam. Cic. Condenar á, ó imponer una pena. - Tributa. Cic. Inponer tributos. - Privilegia. Cic. Dar, conceder privilegios. Irrogassit. ant. Cic. en lugar de Irrogaverit.

Prūdentia, æ. f. Cic. Prudencia, sabiduría. I Ciencia, conocimiento, inteligencia, práctica IIngenio, entendimiento, habilidad, capacidad IPrudencia, virtud.

Sacrāmenta, ōrum. n. plur. Juv. Soldados, tropa, milicia. IEccl. Los sacramentos. I Los misterios de la religión católica.

\section{SIGLO XIX}

Además de continuar editándose los diccionarios de Nebrija ${ }^{76}$, y el Thesaurus $^{77}$ y el Compendium $^{78}$ de Bartolomé Bravo, en este siglo se prodigan las ediciones del Diccionario universal latino-español de Manuel Valbuena. Tal como lo concibió su autor se publicó al menos en siete ocasiones (Madrid, 1808; Madrid, 1817; Madrid, 1819; Madrid, 1822; Madrid, 1826; Madrid, 1829 y Madrid, 1833) ${ }^{79}$, y otras muchas con las correcciones de Vicente Salvá, Pedro Martínez López, Agustín Rocagomera y Salasán, y Miguel de Toro Gómez. La primera edición de Salvá ${ }^{80}$ es, según Antonio Palau (1948-1977: XXIV, n. ${ }^{\circ}$ 346976), la parisina de $1832^{81}$, en ella no hay grandes cambios en el título, solo la supresión

\footnotetext{
${ }^{76}$ Al menos una con las correcciones de Eugenio Ceballos (Gerona, 1800) y otra con las mejoras introducidas por Juan Cayetana Losada (Madrid, 1837); ambas citadas por Guerrero Ramos (1995). De Losada, Palau cita otra edición de 1843 (1948-1977: VII, n. ${ }^{\circ}$ 142571).

${ }^{77}$ Se conservan ejemplares como mínimo de veinticuatro ediciones: Alcalá, 1800; Barcelona, 1807; Madrid (Tipografía de la viuda de Plácido Barco López), 1808; Madrid (Tipografía de D. José Collado), 1808; Barcelona, 1817; Madrid, 1817; Madrid, 1819; Valladolid, 1821; Barcelona, 1824; Valladolid, 1824; Barcelona, 1826; Madrid (Tipografía de Julián de Viana Razola), 1828; Madrid (Imprenta que fue de Fuentenebro), 1828; Barcelona (Sierra), 1831; Barcelona, (Viuda de Antonio Bruso), 1831; Barcelona, 1833; Barcelona (Juan y Jaime Gaspar), 1834; Barcelona, (Tomás Gaspar), 1834; Barcelona (Antonio y Francisco Oliva), 1834; Madrid, 1834; Madrid, 1838; Gerona, 1843; Barcelona, 1850; Madrid, 1860 (Véanse Medina Guerra 1994b: 640-659 y el Catálogo colectivo del patrimonio bibliográfico español).

${ }^{78}$ Entre ellas, Barcelona, 1800; Madrid, 1805; Barcelona, 1807; Madrid, 1810; Madrid, 1817; Madrid, 1821; Barcelona (Sierra y Martí), 1826; Barcelona (Antonio Bruso), 1826; Madrid, 1829; Madrid, 1830; Barcelona, 1832; Barcelona, 1837; Madrid, 1857. Véanse Medina Guerra 1994b: 690-698 y el Catálogo colectivo del patrimonio bibliográfico español.

${ }^{79}$ De todas se conservan ejemplares en distintas bibliotecas españolas, incluso de la de 1833, que no consiguió ver Palau (1948-1977: XXIV , n. ${ }^{\circ}$ 346976), por ejemplo, en la Biblioteca Nacional de Madrid con la signatura 1/43486.

${ }^{80}$ Vicente Salvá considera el diccionario de Manuel Valbuena simplemente como una traducción "servil" del compuesto por Boudot. Véase la nota 73.

81 "Hay un ejemplar en la British Library (Sig. G.547) y otro en la Bibliothèque Nationale (Sig. X.9124)" (Azorín 2000: 260).
} 
del término "universal", pero en la siguiente salida (París, 1834) ya se publica con el nombre Nuevo Valbuena o Diccionario latino-español ${ }^{82}$. En cambio, las ediciones con las correcciones y adiciones de Pedro Martínez López ven la luz desde su primera salida, en 1851 (Madrid-París), con el título de Valbuena reformado. Diccionario latino-español aumentado con más de 20.000 voces [...] lleva además un Vocabulario español-latino ${ }^{83}$, y en el prólogo se ataca las ediciones corregidas por Salvá, a quien se le reprocha su falta de rigor y seriedad en la revisión del diccionario de Valbuena ${ }^{84}$. Por su parte, Agustín Rocagomera y Salasán lo publica con el título de Novísimo Valbuena: completísimo diccionario latino-español formado sobre los mejores diccionarios nacionales y estranjeros: con numerosisimas voces, acepciones y modismos empleados por los autores clásicos latinos y que no se hallan reunidos en ningun otro diccionario latino-español publicado hasta el presente (Barcelona, 1865) ${ }^{85}$, mientras que Miguel de Toro Gómez

${ }^{82}$ En el Catálogo colectivo del patrimonio bibliográfico español, se recogen ejemplares de veintidós ediciones con este título: Valencia, 1840; París, 1843; Valencia, 1846; París, 1846; París, 1850; Valencia, 1850; México, 1852; Valencia, 1852; Santiago, 1854; París, 1854; París, 1857; París, 1858; París, 1861; París, 1862; París, 1865; Madrid, 1865; París, 1873; París, 1878; París, 1880; París, 1885; París, 1888; París, 1893.

83 Según el Catálogo colectivo del patrimonio bibliográfico español, se conservan en distintas bibliotecas españolas, además de la de 1851, ejemplares de otras veinte ediciones: París, 1853: París, 1855; Madrid, 1865; París, 1866; Madrid, 1868; Madrid, 1870; Madrid, 1872; Madrid, 1876; Madrid, 1878; Madrid, 1879; Madrid, 1881; Madrid, 1882; Madrid, 1884; Madrid, 1886; Madrid, 1887; Madrid, 1889; Madrid, 1890; Madrid, 1892; Madrid, 1893; Madrid, 1894. No se recogen en este catálogo las siguientes ediciones de las que se conservan ejemplares en la Biblioteca Nacional de Madrid: París, 1859 (1/61818); Madrid, 1862 (7/52213); Madrid, 1874 (4/202707); Madrid, 1898 (4/40799; 4/139428).

${ }^{84}$ Las críticas y los reproches a las ediciones de Salvá se hallan a lo largo de todo el prólogo, valga como muestra el siguiente fragmento: "Se puede responder con mucho fundamento que en una obra tan voluminosa, compuesta de artículos tan variados, tan inconexos, un desliz venial [...] en alma cualquiera cabe. Cierto es, uno, dos, diez, treinta y aun sesenta hubieramos pasado y perdonado con voluntad hidalga y cristiana, mas al ver que en SEIS ED. muy mejoradas, muy corregidas y muy aumentadas, los desatinos [...] cuentan por millares; al ver que esos desatinos existen todos en el diccionario latino-español de D. Manuel Valbuena ed. de Madrid; al ver en fin, que el S. Salvá admite esos desatinos como sustancia de buena ley, no obstante haberlos leído doce veces por lo menos, aun cuando á dos solamente echemos en primera y segunda prueba de cada una de sus seis ediciones, sobra la razon para afirmar que el S. Salvá puso empeño en rebajar el mérito del libro de Valbuena, tratando á este de plagiario, de descuidado y de ignorante, no mas que con la mira de un interés mercantil, interés despreciado de los hombres que de veras atienden al progreso de las letras [...]. Dedúcese de todo eso que si la obra de D. Manuel Valbuena llegó mala y malparada á manos de D. V. Salvá, en esas manos no adquirió la mas insignificante mejora. Fue una inicua mentira el enfático reclamo que el librero puso en forma de prólogo á aquella obra usurpada [...]" ("Prologo" de 1851, reproducido de en la edición madrileña de 1853, de la que utilizo el ejemplar conservado en la Biblioteca General de la Universidad de Granada con la signatura BHR/B-019-085). Antonio Palau y Dulcet (1948-1977: XXIV, n. ${ }^{\circ}$ 346990) afirma que "Salvá contestó inmediatamente y que, en consecuencia, en algunos ejemplares de la edición [de 1851] se intercaló o sustituyó la anteportada con una hoja impresa en cuyo dorso figura la siguiente nota: «Por no molestar la atención de los jóvenes alumnos a que está destinado el presente libro, seremos breves en la respuesta que debemos dar a los editores del DICCIONARIO LATINO-ESPAÑOL DE VALBUENA, publicado por D. Vicente Salvá hace treinta años, encabezando la última tirada de esta obra con una advertencia contra la publicación del mismo Diccionario que ha reformado D. Pedro Martínez López, y nosotros hemos dado a luz. Primeramente seguimos afirmando que son ciertos los errores señalados en el Diccionario de Salvá, y en segundo lugar que estando clisado hace ya treinta años, no existen en realidad los supuestos aumentos que se anuncian como nuevos; pues siendo inmóviles los caracteres en esa clase de impresiones, era preciso que se hubiesen inutilizado planas enteras, o cuando menos suprimido otros tantos renglones cuantos fueran los nuevos que se pretende haber añadido»"”.

${ }^{85}$ Conoció otras ediciones como las barcelonesas de 1876, 1883 o 1888. 
revisará y aumentará las ediciones corregidas por Salvá con el nombre de Novísimo diccionario latino-español (París, 1895) ${ }^{86}$.

A pesar de su éxito, el Diccionario universal latino-español de Valbuena y sus ediciones a cargo de Salvá y Martínez López serán objeto de crítica por parte de Raimundo de Miguel y el marqués de Morante, Joaquín Gómez de la Cortina, como consta en el prólogo de su Nuevo diccionario latino-español etimológico (Leipzig, 1867) ${ }^{87}$ :

Gran servicio prestó sin duda alguna à su país el insigne académico y doctísimo humanista D. Manuel Valbuena con la publicación del Diccionario que tan popular hizo su nombre entre nosotros [...]. Pero, preciso es confesarlo, sea porque los modelos que se propuso imitar no fuesen los más recomendables, sea porque sus ocupaciones, su edad ó sus achaques no le permitiesen consagrar el tiempo necesario á un trabajo forzosamente rudo, asiduo, tenaz y porfiado, sea porque la falta de práctica en la enseñanza le impidiese parar la atención en pormenores que no pueden apreciarse en teoría, sea en fin por otras causas que no alcanzamos, pero que á no dudarlo fueron independientes de su voluntad y buen deseo; es lo cierto que su obra salio plagada de descuidos que contrastaban lastimosamente con el acertado plan seguido en ella y con la justa y merecida reputacion de su autor [...]. Cuando pasados muchos años vino á anunciarnos la voz publica que se habia proyectado y se hallaban próximas á realizarse, casi simultáneamente, dos nuevas ediciones del Diccionario de Valbuena, reformadas por dos escritores diferente, ambos españoles, ambos entendidos [...] nos alegramos en nuestros corazones [...]. Al poco tiempo nos enviaron las infatigables prensas de París las dos anunciadas reimpresiones; pero cuál sería nuestra sorpresa, cuál nuestro dolor cuando habiendo hojeado una vez y otra los nuevos ejemplares vimos defraudada nuestra esperanza por completo, y llegamos á adquirir un plenísimo convencimiento de que no tan solo se habian mantenido los más de los errores del Valbuena primitivo, sino que se habian agregado otros innumerables, dejandole tan mal parado que apenas puede abrírsele sin tropezar aquí y allí con los descuidos más groseros, con los errores más inconcebibles (p. VII).

Precisamente, los numerosos errores que a cada paso se encuentran, por ejemplo, en orden alfabético, en la cantidad vocálica, en la ortografía o en la interpretación de las palabras en el Valbuena reformado de Martínez López ${ }^{88}$, llevaron a estos autores a emprender su obra con la intención no solo de servir de guía a los estudiantes, sino también, con la de limpiar la imagen de España en el extranjero ("Prólogo", p. VII). Además de corregir las equivocaciones y contradicciones que se hallaban en el diccionario de Valbuena

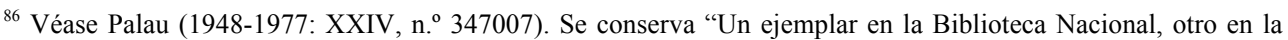
British Library (sig. 12.935.g.3) y uno más en la Bibliothèque Nationale (sig. X.492)” (Azorín 2000: 260).

${ }^{87}$ Utilizo el ejemplar conservado con la signatura B/A/ETIM/RAIMUNDO en el Departamento de Filología Griega y Latina de la Facultad de Filología de la Universidad de Sevilla.

${ }^{88}$ Para Raimundo de Miguel y el marqués de Morante los errores más importantes son comunes a los tres, pero, según puede deducirse del "Prólogo" (pp. VII-XIII), el texto que se pone en evidencia minuciosa y detalladamente es el Valbuena reformado de Martínez López, obra que estos autores toman como punto de partida. Es más, al igual que en el Valbuena reformado, en el Nuevo diccionario latino-español etimológico [...], al cuerpo del diccionario le sigue un "Breve diccionario español-latino", probablemente compendio del Diccionario universal español-latino de Manuel de Valbuena. Se sustituye, sin embargo, el apéndice "Diferencia y contraposición de las voces latinas" del Martínez López, que ya se recogía en las primeras ediciones realizadas bajo la supervisión de Valbuena, por el de "Sinónimos latinos".
} 
enmendado por Martínez López, enriquecen la obra con nuevos artículos ${ }^{89}$ y prestan especial atención a la etimología, la sintaxis y la pronunciación; se trata, por tanto, de un "Diccionario á un mismo tiempo etimológico, porque indica el orígen ó derivación de casi todas las palabras; de sintaxis, porque señala el régimen y construccion de las mas importantes; y prosódico porque fija la cantidad de todas ellas" ("Prólogo", p. XV). Este repertorio gozó de una gran acogida por parte del público y siguió editándose hasta bien entrado el siglo $\mathrm{XX}^{90}$.

Junto con las numerosas y reiteradas correcciones del diccionario latino-español de Valbuena, a las que acabo de hacer referencia, en esta centuria ve también la luz el diccionario español-latino de este mismo autor, impreso, tras su muerte ${ }^{91}$, en Madrid en 1822, con el título de Diccionario universal español-latino ${ }^{92}$. En el "Prólogo" se afirma que se toma como modelo, en la parte española, la quinta edición (Madrid, 1817) del Diccionario de la lengua castellana de la Real Academia Española del que se ha omitido las voces de germanía y las anticuadas ${ }^{93}$, y al que se sigue en las definiciones "[...] compendiándolas en lo posible, y sustituyendo sinónimos donde [...] ha parecido mas conveniente usar de ellos que de una definicion que deja à veces mas oscuro lo que se define". En la parte latina, se copia la información recogida en el Diccionario universal latino-español y se afirma que se ha procurado aprovechar lo más selecto de los diccionarios modernos y antiguos, entre los que Valbuena destaca el de Alfonso Sánchez de la Ballesta, porque "[...] encierra un tesoro abundante, tanto de expresiones de selecta latinidad, como de curiosas noticias que desenvuelven el sentido misterioso y oculto en los adagios ó proverbios tomados de los mismos latinos".

\footnotetext{
89 "Sesenta mil novecientos setenta y uno son, entre todos, los artículos comprendidos en el Diccionario reformado de Valbuena; setenta mil doscientos doce contiene el nuestro; de manera que el segundo cuenta en sus columnas nueve mil doscientos cuarenta y una voces más que el primero" ("Prólogo", p. XIII)

${ }^{90}$ Entre las ediciones que vieron la luz en el siglo pasado se encuentran, por ejemplo, las siguientes: Madrid, 1908; Madrid, 1919; Madrid, 1929; Madrid, 1931; Madrid, 1946.

${ }^{91}$ Según se advierte en la dedicatoria al rey, firmada por Antonio Martín Heredia: "Y habiéndole ayudado mi corto talento por espacio de cuatro años à coordinar y rectificar los trabajos que tenia hechos, y que sus continuos males le impedian dirigir; cumpliendo con la última voluntad del distinguido, laborioso y patriota D. Manuel de Valbuena y el deseo de su digna viuda, ruego a V. M. Reciba y proteja esta obra con la amabilidad con que se ha dignado a acoger otras del mismo autor".

${ }^{92}$ Este diccionario merecerá la alabanza de Martínez López en el "Prólogo" de su Valbuena reformado: "Que à Valbuena se le había de estudiar, no en su Diccionario latino-español donde no hizo ni pudo hacer mas que ceñirse à la opinión de la generalidad de aquellos intérpretes, sino en su Diccionario español-latino, obra en la cual brilla el sabor del ilustre académico, aunando la correspondencia de las dos lenguas con expresiones, á mas de exactas y acertadas, desconocidas hasta entonces de cuantos lexicógrafos le habían precedido [...]".

${ }^{93}$ Si bien, de estas últimas se incluye una lista, a modo de apéndice, en la que se recogen aquellas "que conservan [algún uso] con su equivalente usual al frente, para que asi pueda buscarse en el cuerpo del Diccionario su traduccion latina”. En este apéndice, que abarca de la página 1116 a la 1124, se recogen 1226 voces, aunque a estas no siempre les siguen un sinónimo lo que dificulta su localización en el cuerpo del diccionario, por ejemplo, "Forista. Versado en los fueros; Galicinio. El tiempo próximo al amanecer; Gavillada. Lo que el ladrón junta con sus robos; Guácharo, ra. El que está continuamente lamentándose; Idromiel. Confeccion de zumo de manzanas y miel".
} 
En ediciones posteriores, como la parisina de $1852^{94}$, se reduce el formato del diccionario con la intención de hacerlo más manejable ${ }^{95}$; con este fin se resumirán o suprimirán algunas definiciones de la parte española y se tenderá a un mayor uso de abreviaturas ${ }^{96}$ :

Arcabucear. v. a. mil. Quitar la vida á escopetazos, pasar por las armas. More militari morte multare; catapultis aliquem supplicii causa petere (1822).

Arcabucear. v. a. mil. Pasar por las armas. More militari morte multare; catapultis aliquem supplicii causa petere (1852).

Botonazo. m. esgr. El golpe que se da con el boton de la espada negra. Ensis propilatis ictus (1822).

Botonazo. m. esgr. Ensis prœpilatis ictus (1852).

Botoral. adj. cir. Se aplica á la apostema pequeña. Parvus, exiguus abscenssus, tumor (1822).

Botoral. adj. cir. Parvus, exiguus abscenssus, tumor (1852).

Cambalache. m. fam. Cambio y trueque de una cosa de poco valor por otra. Permutatio, commutatio (1822).

Cambalache. m. fam. Permutatio, commutatio (1852).

Casucha. f. fam. Casa pequeña y despreciable. Domuncula, cassula, æ (1822).

Casucha. f. fam. Domuncula, cassula, æ (1852).

Congestion. f. med. Porcion de humores detenidos en alguna parte del cuerpo. Congestio (1822).

Congestion. f. med. Porcion de humores. Congestio (1852).

Algún error debió existir en la impresión, pues, en la edición de 1852 aparecen inconclusos artículos que no lo están en la de 1822:

Bonachon. m. aum. El que tiene el genio dócil, y todo lo cree sin examen. Blandus, valde benignus (1822)

Bonachon. m. aum. (1852).

\footnotetext{
${ }^{94}$ Utilizo el ejemplar conservado en la Biblioteca de Filología de la Universidad de Sevilla con la signatura 4/440

${ }^{95}$ En la segunda mitad del siglo, buscando facilitar el manejo de los repertorios lexicográficos y abaratar su impresión, se publicaron también distintos diccionarios manuales como, por ejemplo, el Diccionario manual de la lengua castellana con la correspondencia latina (Barcelona, 1850) de Pedro Labernia y Esteller, el Novisimo diccionario manual español-latino y latino-español redactado en visa del Ximenes, Valbuena, Salvá, Calepino, Requejo, etc. (Barcelona, 1853) de Leandro Cabadijar o el Diccionario manual latino-español (Madrid, 1888) de Francisco Jiménez Lomas.

${ }^{96}$ Entre ellas, en esta edición, se emplea curiosamente germ. para marcar las voces de germanía, que, como ya se ha dicho, se suprimieron de la de 1822 del cuerpo del diccionario.
} 
Cimborio ó cimborrio. m. arq. El cuerpo que cargando sobre los cuatro arcos torales y sus pechinas es compuesto de zócalo, pedestal, cuerpo de luces, media naranja y pedestal. Tholus, i; testudo, inis (1822).

Cimborio ó (1852).

Cimbalillo y cimbanillo. m. Campana pequeña. Tintinnabulum.i (1822).

Cimbalillo y (1852).

Coplero y coplista. m. El que hace coplas. Cantilenarum (1822).

Coplero y (1852).

Elemental y elementar. adj. Perteneciente á los primeros elementos ó al que los aprende. Elementarius, elementitius, a, um [...] (1822).

Elemental y elementar (1852).

Con más o menos actualizaciones, el diccionario español-latino de Valbuena se editó en distintas ocasiones ${ }^{97}$ hasta que fue corregido y publicado por Agustín Rocagomera y Salasán con el título de Novísimo Valbuena: completísimo diccionario español-latino formado sobre los mejores diccionarios nacionales y extranjeros [...] (Barcelona, 1866) ${ }^{98} \mathrm{y}$ por Miguel de Toro Gómez, bajo el nombre de Novísimo diccionario español-latino (París, $1897)^{99}$.

En definitiva, este recorrido por los principales diccionarios con el latín y el español pone de manifiesto que en esta parcela nuestra lexicografía se muestra, en gran parte, deudora de la italiana, inspirándose primero en los grandes diccionarios monolingües latinos y después en los bilingües y plurilingües publicados en Italia. Así, los lexicógrafos españoles toman como punto de partida las obras de Papias, Giovanni Bernardo da Savona, Ambrogio Calepino, Mario Nizzoli o Egidio Forcellini, si bien, no obvian, aunque, como hemos visto, sin llegar a comprenderla del todo, la labor emprendida por Nebrija, cuyos diccionarios siguieron publicándose hasta bien entrado el siglo XIX gracias a las adiciones y correcciones, entre otros, de López Rubiños o Eugenio Ceballos. Y es que los repertorios nebrisenses, hitos de la lexicografía española, carecían de citas y ejemplos, elementos imprescindibles para cumplir la función didáctica con la que nacen las obras, por ejemplo, de Sánchez de la Ballesta, Bravo o Valbuena, destinadas a jóvenes estudiantes de latín, de ahí la necesidad de volverse a los modelos italianos.

\footnotetext{
${ }^{97}$ Al menos en las siguientes: Valencia, 1853; París-México, 1854; París-México, 1859; París, 1860 (Véase el Catálogo colectivo del patrimonio bibliográfico español).

${ }^{98}$ Con este título se publica además en Barcelona, 1878, Barcelona, 1883; París, 1897 (Véase el Catálogo colectivo del patrimonio bibliográfico español).

${ }^{99}$ Véase Palau (1948-1977: XXIV, n. ${ }^{\circ}$ 347008).
} 


\section{REFERENCIAS BIBLIOGRÁFICAS}

ACERo DurÁNTEZ, I. (2003). "La lexicografía plurilingüe del español”. Lexicografía española, A. M. Medina Guerra (coord.), Barcelona, Ariel, 175-204.

Alvar López, M. (1982). "Del glosario al diccionario automatizado". La lengua como libertad y otros estudios, Madrid, Cultura Hispánica, 103-121.

Alvar EzQuerra, M. (2002a). "El largo viaje hasta el diccionario monolingüe". De antiguos y nuevos diccionarios, Madrid, Arco/Libros, 85-108.

Alvar EzQUerra, M. (2002b). "Los primeros siglos de nuestra lexicografía”. De antiguos y nuevos diccionarios, Madrid, Arco/Libros, 51-84.

Alvar EzQuerra, M. (2002c). "Nebrija, autor de diccionarios". De antiguos y nuevos diccionarios, Madrid, Arco/Libros, 120-131.

Alvar EzQuerra, M. (2002d). "Los diccionarios del español en su historia". De antiguos y nuevos diccionarios del español, Madrid, Arco/Libros, 13-50.

Alvar EzQuerra, M. (2002e). "Nebrija, ¿comprendido?, en De antiguos y nuevos diccionarios del español, Madrid, Arco/Libros, 132-142.

Álvarez DE MirandA, P. (1992). "En torno al Diccionario de Terreros". Bulletin Hispanique 94/2, 559-572.

ANTONIO, N. (1783-1788). Bibliotheca hispana nova sive hispanorum scriptorum qui ab anno MD ad MDCLXXXIV. Floruere notitia, I, Madrid, Joaquín Ibarra; II, Madrid, Viuda e hijos de J. Ibarra.

AZORÍN FERNÁNDEZ, D. (2000). Los diccionarios del español en su perspectiva histórica, Alicante, Universidad.

BURIDANT, C. (1986). "Lexicographie et glossographie médiévales. Esquisse de bilan et perspectives de recherche". Lexique 4 (= La lexicographie au Moyen Âge, C. Buridant, coord.).

CASTro, A. (1991 [1936]). "Estudio preliminar". Glosarios latino-españoles de la Edad Media, Madrid, CSIC, V-LXXXIII.

CATÁLOGO colectivo del patrimonio bibliográfico español. Ministerio de Cultura, 13-52008, htpp://www.mcu.es/patrimoniobibliografico/buscarPatrimonioBibliografico.do

CEJADOR y FRAUCA, J. (1972 [1929-1933]). Historia de la lengua y la literatura castellana, Madrid, Gredos, ed. facsimilar.

COLÓN, G., A-J. SoberanAS (1979). Estudio preliminar de la edición facsimilar del Diccionario latino-español (Salamanca, 1492) de Antonio de Nebrija, Barcelona, Puvill.

CORPAs PAStOR, G. (1996). Manual de fraseología española, Madrid, Gredos. 
FABBRI, M. (1979). A bibliography of hispanic dictionaries: catalan, galician, spanish, spanish in Latin America and the Philippines, Imola, Galeati.

Gallina, A. (1959). Contributi alla storia della lexicografía italo-spagnola dei secoli XVI e XVII, Florencia, L. S. Olschi.

GARCíA MACHO, L. (1987). “Algunas consideraciones en torno al Vocabulario y al Diccionario de Elio Antonio de Nebrija”. Revista de Filología Española 67, 89-105.

García Platero, J. (2003). "La lexicografía no académica en los siglos XVIII y XIX”. La lexicografía española, A. M. Medina Guerra (coord.), Barcelona, Ariel, 263-280.

GEMmingen, B. F. von (2003). "Los inicios de la lexicografía española”. La lexicografía española, A. M. Medina Guerra (coord.), Barcelona, Ariel, 151-174.

Gili GayA, S. (1960). Tesoro lexicográfico (1492-1726), I (A-E), Madrid, CSIC.

GILI GAYA, S. (1967). "Nota preliminar" de la edición facsímil de la edición de Sevilla de 1490 del Universal vocabulario de A. de Palencia, I, Madrid, Comisión Permanente de la Asociación de Academias de la Lengua Española, 5-6.

GONZÁLEZ GONZÁlez, E. M. (1998-1999). "Las expresiones paremiológicas en el Dictionario de Alonso Sánchez de la Ballesta: propuesta de sistematización”. Revista de Lexicografia 5, 69-87.

Guerrero Ramos, G. (1995). El léxico en el Diccionario (1492) y en el Vocabulario (¿1495?) de Nebrija, Sevilla, Universidad de Sevilla, Ayuntamiento de Lebrija.

HaZAÑAS Y LA RúA, J. (1909). Maese Rodrigo 1444-1509, Sevilla, Izquierdo y Comp.

INDICE General degli Incunaboli delle Biblioteche d'Italia (1943-1981), Roma, Libreria dello Stato, Poligrafica dello Stato.

LABARre, A. (1975). Bibliographie du Dictionarium d'Ambrogio Calepino, Baden-Baden, V. Koerner.

MEdinA Guerra, A. M. (1991). "Modernidad del Universal Vocabulario de Alfonso Fernández de Palencia". Estudios de Lingüistica. Universidad de Alicante 7, 45-60.

Medina Guerra, A. M. (1993). "Fuentes del Dictionario de Sánchez de la Ballesta". Revista de Filología española 73, 379-390.

Medina Guerra, A. M. (1994a). “Apuntes biográficos sobre Rodrigo Fernández de Santaella”. Analecta Malacitana 17/1, 145-151.

Medina Guerra, A. M. (1994b). Los diccionarios bilingües con el latín y el español (14901619), Málaga, Universidad.

Medina Guerra, A. M. (1996a). "Los diccionarios latín-español de Elio Antonio de Nebrija y Rodrigo Fernández de Santaella”. Estudios de historia de la lexicografía del español, M. Alvar Ezquerra (coord.), Málaga, Universidad, 27-34. 
Medina Guerra, A. M. (1996b). "Giovanni Bernardo da Savona en los inicios de los diccionarios italianos y españoles". Scripta philologica in memoriam Manuel Taboada Cid, M. Casado Velarde et al. (eds.), La Coruña, Universidad, t. I, 157-163.

Medina GuerrA, A. M. (1996c). "Epígonos de Rodrigo Fernández de Santaella". Segundas Jornadas sobre el Estudio y la Enseñanza del Léxico, J. D. Luque Durán y A. Pamies Bertrán (eds.), Granada, Método, 121-130.

Medina Guerra, A. M. (1996d). "Referencias a Fernández de Santaella en el Lexicon ecclesiasticum de Diego Jiménez Arias". Revista de Filología Española 76, 131-140.

Medina Guerra, A. M. (1996e). “Alonso Sánchez de la Ballesta, ¿seudónimo?”. Estudios de historia de la lexicografia del español, M. Alvar Ezquerra (coord.), Málaga, Universidad, 43-45.

Medina Guerra, A. M. (1997). "Las fuentes del Thesaurus de Bartolomé Bravo". Estudios de lingüistica general. Trabajos presentados en el II Congreso Nacional de Lingüistica General, J. A. Molina Redondo y J. D. Luque Durán (eds.), Granada, Método, 315-322.

Medina Guerra, A. M. (1998a). Las ediciones del Vocabularium seu Lexicon ecclesiasticum de Rodrigo Fernández de Santaella y Jiménez Arias (1499-1798), Málaga, Universidad.

Medina Guerra, A. M. (1998b). "El Dictionario de Sánchez de la Ballesta en los repertorios paremiológicos posteriores". Estudios de Lingüística General, F. Delgado León, M. L. Calero Vaquera y F. Osuna García (eds.), Córdoba, Universidad, 391-399.

Medina Guerra, A. M. (2000). "Giovanni Bernardo da Savona y Nicolas de Lyra en el Vocabularium ecclesiasticum”. Revista de Filología Española 80, 223-232.

Medina Guerra, A. M. (2001a). "El Vocabularium ecclesiasticum de Rodrigo Fernández de Santaella y el Lexicon ecclesiasticum de Diego Jiménez Arias frente a frente". Estudios de lexicografia diacrónica del español (V Centenario del Vocabularium Ecclesiasticum de Rodrigo Fernández de Santaella), A. M. Medina Guerra (coord.), Málaga, Universidad, 5978.

Medina Guerra, A. M. (2001b). "En torno a la preparación de una edición crítica del Vocabularium ecclesiasticum de Rodrigo Fernández de Santaella". Tendencias en la investigación lexicográfica del español, S. Ruhstaller y J. Prado Aragonés (eds.), Huelva, Universidad, 137-150.

MENÉNDEZ y Pelayo, M. (1902). Bibliografia hispano-latina clásica, I, Madrid, Viuda e hijos de M. Tello.

NiedereHe, H. J. (1986). "Das Universal Vocabulario des Alonso Fernández de Palencia (1490) und seine Quelle". The History of Linguistics in Spain, A. Quilis y H. J. Niederehe (eds.), Ámsterdam / Filadelfia, J. Benjamins, 39-54.

OLIVIERI, O. (1942). "I primie vocabulari italiani fino alla prima edizione della Crusca". Studi di Filologia 6, 64-192. 
PAlAU Y DUlCET, A. (1948-1977). Manual del librero hispanoamericano. Bibliografia general española e hispanoamericana desde la invención de la imprenta hasta nuestros tiempos con el valor comercial de los impresos descritos, Barcelona, A. Palau, 28 vols.

PAZ y Melí́, A. (1914). El cronista Alonso de Palencia, su vida y sus obras; sus décadas y las crónicas contemporáneas; ilustraciones de las décadas y notas varias, Madrid, The Hispanic Society of America-Tipografía de Revista de Archivo.

PÉREZ GoyenA, A. (1947-1964). Ensayo de bibliografia navarra desde la creación de la imprenta en Pamplona hasta el año 1910, Pamplona, Institución Prícipe de Viana, 9 vols.

PERONA, J. (1991). "Latina uocabula ex iure ciuili in uoces hispanienses interpretata. II, 1 de Elio Antonio de Nebrija". CLHM 16, 189-365.

RosSEBASTIANO BART, A. (1986). "Alle origini della lexicografía italiana". Lexique 4 (= La lexicographie au Moyen Âge, C. Buridant, coord.), 113-156.

Salvá y Mallén, P. (1872). Catálogo de la biblioteca de Salvá, Valencia, Ferrer de Ortega, 2 vols.

Antonia María Medina Guerra

ammedina@uma.es

Dpto. Filología Española II y Teoría de la Literatura

Campus de Teatinos, $\mathrm{s} / \mathrm{n}$

29071 Málaga 